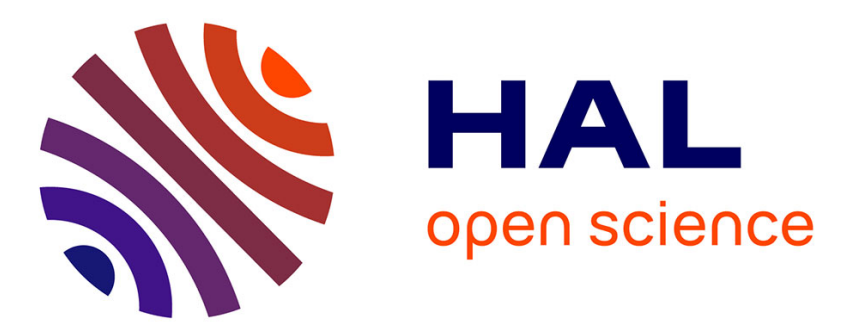

\title{
Central bank Transparency and Information Dissemination: An experimental Approach
}

Emna Trabelsi, Walid Hichri

\section{To cite this version:}

Emna Trabelsi, Walid Hichri. Central bank Transparency and Information Dissemination: An experimental Approach. 2013. halshs-00915667

\section{HAL Id: halshs-00915667 https://shs.hal.science/halshs-00915667}

Preprint submitted on 9 Dec 2013

HAL is a multi-disciplinary open access archive for the deposit and dissemination of scientific research documents, whether they are published or not. The documents may come from teaching and research institutions in France or abroad, or from public or private research centers.
L'archive ouverte pluridisciplinaire HAL, est destinée au dépôt et à la diffusion de documents scientifiques de niveau recherche, publiés ou non, émanant des établissements d'enseignement et de recherche français ou étrangers, des laboratoires publics ou privés. 
Central bank Transparency and Information Dissemination: An experimental Approach

Walid Hichri, Emna Trabelsi

December 2013 


\section{GATE Groupe d'Analyse et de Théorie Économique Lyon-St Étienne}

93, chemin des Mouilles 69130 Ecully - France

Tel. +33(0)4 72866060

Fax $+33(0) 472866090$

6, rue Basse des Rives 42023 Saint-Etienne cedex 02 - France

Tel. +33 (0)4 77421960

Fax. +33 (0)4 77421950

Messagerie électronique / Email : gate@gate.cnrs.fr

Téléchargement / Download : http://www.gate.cnrs.fr - Publications / Working Papers 


\title{
Central bank Transparency and Information Dissemination: An experimental Approach
}

\author{
Emna Trabelsi* and Walid Hichri ${ }^{\dagger}$
}

December 2, 2013

\begin{abstract}
In this paper, we propose to compare different partial transparency regimes in order to determine the optimal diessmination policy by the central bank, using an experimental approach. A treatment dedicated to the benchmark situation (where information is fully released) is also available. Our experiment is based on subsequent framework of Morris and Shin (2002), Cornand and Heinemann (2008) and Trabelsi (2012). The predictive power of K-level reasoning is an issue that is addressed also in this paper. Our experiment indicates that -when fully disclosed- players overreact to public information and this overreaction is efficiently reduced when the degree of publicity decreases (i.e. when the fragmentation measure increases). The average weight assigned to common signal decreases over treatments, especially when we establish partial transparent strategy (i.e. fragmented information). The results provide support both for and against global games theoretical predictions. In fact, although players overreact to public signal, their behavior is inconsistent with theoretical equilibrium, which means that the destabilizing effect of public information is less pronounced experimentally than when it does in theory. This is not the case when public information is fragmented; subjects' behavior does approach equilibrium. These observations coincide with both a collective and an individual analyses of behavior.
\end{abstract}

JEL classification: E58, D82, C93

Keywords: Central bank transparency, coordination games, semi-public information, private information, experimental economics

\section{Introduction}

Central bank communication is an important aspect in implementing an efficient and effective monetary policy stance. Central banks have focused on greater transparency by enlarging the modes of communication.

Central banks make use of a wide range of communication tools, whose objective is to help private agents to understand the contribution that monetary policy is intended to make to economic and price developments over time and helps to anticipate the broad direction of the monetary policy over the medium term. This guidance reinforces the predictability of policy statements and affects expectations regarding the future path of interest rates, thereby making the policy more effective. Although it is widely accepted that improved transparency of monetary policy and the associated communication have been effective (Trabelsi and Ayadi, 2011), the question remains if a central bank should reveal more information to the public, thereby making its communication more explicit and forward looking.

The issue of central bank transparency has been discussed in several aspects ${ }^{1}$. This paper relates specifically to the approach taken in coordination games. This strand of literature supports that communication may in certain circumstances, be undesirable and counterproductive (Morris and Shin (2002), Amato et al. (2002) and Padoa-Schioppa (2004)).

\footnotetext{
*Corresponding Author. Institut Supérieur de Gestion de Tunis (ISG Tunis). 41 Avenue de la Liberté, cité Bouchoucha, le Bardo, 2000. Tunisia. E-mail: emna.trabelsi2007@yahoo.fr. Mobile: 0021621310931.

†Université de Lyon, Lyon, F-69007, France ; CNRS, GATE Lyon Saint-Etienne, Ecully, F-69130, France, Université Lyon 2, Lyon, F-69007, France \& Laboratoire de Recherche en Économie Quantitative du Développement (LAREQUAD). E-mail: hichri@gate.cnrs.fr.

${ }^{1}$ See Blinder et al. (2008) for an overview of theory.
} 
There are obviously limits to how information can be digested effectively (Gai and Shin, 2003). The central bank must be careful to communicate issues on which it may receive noisy signals itself ${ }^{2}$. This issue has been remarkably highlighted by Morris and Shin (2002) in a beauty contest game. Those authors notice that a noisy public signal can lead to greater variability and reduces social welfare when economic agents discard private information in coordinating their actions. Amato, Morris and Shin (2002) argue that communication plays a dual role: on one hand, it provides signals about the private information of the central bank and on the other hand, it serves as a mechanism for coordinating economic agents expectations. They note that the communication can reduce social welfare if agents give more weight to these communications (used as a focal point) and too little on their own information. The central bank can thus coordinate actions away from fundamentals. The result of Morris and Shin (2002) has generated numerous responses and comments, so that Svensson (2006) questioned its plausibility in the sense that the argument advanced by Morris and Shin does not remain in reality. Additionally, Woodford (2003, 2005) notes that the problem of Morris and Shin (2002) is even less likely to arise if the coordination of private agents is a goal of welfare per se. Amador and Weil (2006) argue that additional public information can create confusion among economic agents, slows the dissemination of private information and can reduce social welfare. However, Angeletos and Pavan (2004, 2007) show that the impact of public information depends on the degree of strategic complementarities.

Most of these theoretical studies on informational structure involve accuracy and information nature (public/private). Recently, we focus on the number of receivers as an important component of information and the number of information (i.e Morris and Shin (2007), Cornand and Heinemann (2008)).

In the same context as that of Morris and Shin, Cornand and Heinemann (2008), argue that welfare improves when more public information is only received by a fraction of market participants. According to these authors, limiting publicity of information can reduce the negative externalities associated with high level of transparency. Indeed, public information must be provided with maximum precision, but is not transmitted to all agents. A restriction on the degree of publicity of information will be more effective in avoiding adverse effects from the public announcement than a restriction on the information accuracy.

The key insight in the analysis of Morris and Shin (2002) is that equilibrium players often place too much weight on public signal relative to that would be used by the social planner. Therefore, individual information is not socially efficient and enhanced public disclosure could hurt social welfare. The generelized framework that we use is a modification of Morris and Shin (2002), Cornand and Heinemann (2008) and Trabelsi (2012), respectively. In our setting, just as in the benchmark model, the agents' payoff is determined by two criteria: How well an agent's action matches an unknown state of the world and how well his action matches the average action of other agents. We address in this paper different issues. First, it theoretically analyses the effectiveness of fragmented strategy in reducing the overreaction to public information. Second, it empirically tests the theoretical predictions in a laboratory experiment. Third, we draw some policy guidelines regarding strategies to disclose information to the public. We design several experimental treatments that differ from each other in the number of receivers and or the number of information. Although a brief overview of theoretical findings is provided below, this paper focuses particularly on experimental evidence. The reminder of this paper is as follows, section 2 describes our basic model and the theoretical predictions of Trabelsi (2012); section 3 presents the experimental design, our main results will be discussed in section 4 and section 5 concludes.

\section{Basics of the theoretical model: Modified model of Morris and Shin and its variants}

This section provides a theoretical background for our study. First, based on the Morris and Shin (2007) and on Trabelsi (2012) models, subsequently, we develop the framework that will be used in our experimental design. Then, within this framework, we derive our main results.

There are $N$ identical agents, $j=1,2 \ldots N$. Agent $j$ chooses an action $a_{j}^{i}$. The payoff function of agent $j$ is given by:

$$
U\left(a_{j}^{i}, \bar{a}_{-j}, \theta\right)=u_{0}-(1-r)\left(a_{j}^{i}-\theta\right)^{2}-r\left(a_{j}^{i}-\bar{a}_{-j}\right)^{2}
$$

\footnotetext{
${ }^{2}$ For example, forecasts errors....
} 
Where $u_{0}$ is a constant, $\theta$ represents the fundamental state. $r$ is the degree of strategic complementarities and it is a constant between 0 and 1. $\bar{a}_{-j}=\frac{1}{N-1} \sum_{k \neq j} a_{k}$ is the average action of $j$ 's opponents.

The payoff function has three terms. The first one is a constant $u_{0}$ and is the highest payoff the individual can possibly earn. The second term reflects the loss from mismatching the underlying fundamental $\theta$ and $a_{j}^{i}$. The third term is the "beauty contest" term. It measures the loss from mismatching the average actions of opponents $\bar{a}_{-j}$. The parameter $r$ measures the relative importance of coordinating with opponents' actions versus matching the underlying state. When $u_{0}=0$, the game becomes the coordination game specified in Morris and Shin (2002). When $r=1$, the game becomes similar to the beauty contest in the sense that subjects only need to match the average of the other players' actions.

The payoff function differs from Morris and Shin (2002) in three ways ${ }^{3}$ : First, we consider a setting with a finite number of players, while in Morris and Shin (2002, 2007), Cornand and Heinemann (2008) and Trabelsi (2012) include a continuum of players. Second, the payoff function of Morris and Shin is always negative, which is difficult to implement in laboratory. By adding a positive term to the original function, we allow participants' payoffs to be positive without altering equilibrium predictions. Third, the distribution of the errors is uniform instead of normal.

Briefly, we characterize the equilibrium with respect to the informational structure in Cornand and Heinemann (2008), in which the public signal $y=\theta+\eta$ is released to a fraction $P$ of the population. Each agent has his private signal $x_{j}=\theta+\varepsilon_{j}$.

Both $\eta$ and $\varepsilon$ are i.i.d normally distributed with zero mean and variances $\sigma_{\eta}^{2}$ and $\sigma_{\varepsilon}^{2}$.

The optimal action of an agent $j$ according to whether he receives a public signal or not is as follows:

$$
a_{j}= \begin{cases}\frac{\sigma_{\varepsilon}^{2}}{\sigma_{\varepsilon}^{2}+(1-r P) \sigma_{\eta}^{2}} y+\frac{(1-r P) \sigma_{\eta}^{2}}{\sigma_{\varepsilon}^{2}+(1-r P) \sigma_{\eta}^{2}} x_{j} & j \in[0, P] \\ x_{j} & j \in[P, 1]\end{cases}
$$

As in Trabelsi (2012), before taking actions, agent $j$ will receive two types of signals about $\theta$ and we assume that both signals have the same precision $\alpha$. The first signal is semi-public and is given by:

$$
z_{i}=\theta+\eta_{i} i=1,2, \ldots n
$$

As for the second type of signals $x_{j}^{i}$, it is private, which means that it is specific to each agent:

$$
x_{j}^{i}=\theta+\varepsilon_{j}^{i}
$$

Both $\eta_{i}$ and $\varepsilon_{j}^{i}$ are i.i.d normally distributed with zero mean and variances $\sigma_{\eta}^{2}$ and $\sigma_{\varepsilon}^{2}$.

Morris and Shin assume $\theta$ to have a uniform distribution over the real line in which case the expected value of $\theta$ given $z_{i}$ and $x_{j}^{i}$ is:

$$
E_{j}^{i}(\theta)=\frac{\sigma_{\varepsilon}^{2} z_{i}+\sigma_{\eta}^{2} x_{j}^{i}}{\sigma_{\varepsilon}^{2}+\sigma_{\eta}^{2}}
$$

Following Trabelsi (2012) and using the Bayesian update rule, we can show that the unique equilibrium is linear and is given by:

$$
a_{j}^{i}=\frac{\sigma_{\varepsilon}^{2} z_{i}+\sigma_{\eta}^{2}\left(1-\frac{r}{n}\right) x_{j}^{i}}{\sigma_{\varepsilon}^{2}+\left(1-\frac{r}{n}\right) \sigma_{\eta}^{2}}
$$

Either by establishing a strategy of partial publicity or a fragmented information, the overeaction to public information is reduced. We can summarize the effect of varying the publicity degree $P$ and the fragmentation measure $n$, respectively in this short Table:

\footnotetext{
${ }^{3}$ The utility function in the benchmark model of Morris and Shin $(2002)$ is given by $U^{M S}\left(a_{j}, \theta\right)=u_{0}-(1-r)\left(a_{j}-\theta\right)^{2}-$ $r\left(L_{j}-\bar{L}\right)^{2}$ where $L_{j}=\int_{0}^{1}\left(a_{k}-\theta\right)^{2} d k$ and $\bar{L}=\int_{0}^{1} L_{k} d k$. Since this function is complicated to be implemented in laboratoy, we chose to use (1). As claimed by Cornand and Baeriswyl (2013), working with the utility function described in (1) has no incidence on the theoretical optimal action given by the expression; $a_{j}=(1-r) E_{j}(\theta)+r E_{j}(\bar{a})$. consequently, it doesn't alter the goals of the paper.
} 
Table 1: Equivalence of effects between fragmentation and partial publicity

\begin{tabular}{|c|c|}
\hline & Then the weight on the semi-public signal \\
\hline \hline If $P \downarrow$ & $\downarrow$ \\
\hline If $n \uparrow$ & $\downarrow$ \\
\hline
\end{tabular}

A major difficulty in implementing Morris and Shin set up in the lab is to generate $\theta$ using an improper uniform distribution. To deal with this problem, we adopted the following strategy: we generate $\theta$ using the uniform distribution on interval $[a, b]$ and then given $\theta$, we generated $z_{i}$ and $x_{j}^{i}$ according to (2) and (3).

\section{$3 \quad$ Experimental design matching theoretical model}

\subsection{Payoff function and signals}

In all treatments, the payoff function of a subject $j$ is given by:

$$
U\left(a_{j}^{i}, \bar{a}_{-j}, \theta\right)=\operatorname{Max}\left(0, u_{0}-(1-r)\left(a_{j}^{i}-\theta\right)^{2}-r\left(a_{j}^{i}-\bar{a}_{-j}\right)^{2}\right)
$$

Where $a_{j}^{i}$ is the action of subject $j$, that belongs to group $i, \theta$ is the unknown true state of the world, $\bar{a}_{-j}$ is the average of all subjects' actions except $j$ and $r$ is the relative importance of matching the weighted average of the players' actions.

Since the payoff function given by (6) is more complicated than those in typical laboratory experiments, every effort was made to ensure that subjects understood the payoff structure. First, expression (6) was presented in a simpler manner:

$$
U^{\prime}\left(a_{j}^{i}, \bar{a}_{-j}, \theta\right)=10 \times U\left(a_{j}^{i}, \bar{a}_{-j}, \theta\right)=\operatorname{Max}\left(0, U_{0}-10 \times(1-r)\left(a_{j}^{i}-\theta\right)^{2}-10 \times r\left(a_{j}^{i}-\bar{a}_{-j}\right)^{2}\right)
$$

The fact that payoffs could not be negative was explained to the subjects. Second, we took the advantage of the fact that each term has a simple and an intuitive interpretation. We started by verbally explaining that there are two factors that will determine the mismatching the underlying state and the mismatching the average action made by others. After this was understood, we presented the actual mathematical form, explained the meaning of each term, and went through several numerical examples. Finally, during the actual experiment at the end of each period, the first and the second terms have been calculated and displayed together with $\theta$ and $\bar{a}_{-j}$. This proved to be very helpful for participants since it highlighted how each term in (6) affects the payoff.

All treatments had a quite similar structure and differed only in two aspects: the degree of publicity and fragmentation of the common information, respectively. The state and signals, whether they are public, semipublic or private were generated prior to the experiment. For each period, $\theta$ is generated randomly according to a uniform distribution on [50,950]. Given $\theta$, the signals are independently drawn from a uniform distribution $[\theta-10, \theta+10]$. Signal $y$ is public and is the same for all participants. Signal $z_{i}$ is semi-public and it is the same for all subjects who belong to the same sub-group $i$. Signal $x_{j}^{i}$ is private, that is specific to each player.

\subsection{Treatment and session description}

The experimental methodology followed in this paper is close to that of Cornand and Baierswyl (2013). Two treatments A and B were implemented for this study. They differ with respect to information available to the participants (For parameters and notations, see Table 2). Each treatment consists of three stages. We label stage 1 of both treatments A and B as MS (referring to Morris and Shin), in which participants will receive 1 common signal and 1 private signal per subject. Stage 2 and 3 of treatment A are labelled as T (Referring to Trabelsi), in which participants are divided in $n$ sub-groups, each sub-group receives 1 common signal and 1 private signal per subject. Finally, stage 2 and 3 of treatment B are labelled as $\mathrm{CH}$ (referring to Cornand and Heinemann), in which participants receive again one private signal per subject, but the common signal will be disseminated to only a proportion $P$ of the subjects $(P=0.50$ in stage 2 and $P=0.25$ in stage 3$)$. 
Sessions are based on the one of the two treatments and consist of three stages for a total of 45 periods, three times 15 periods (per stage). The value of $r$ is fixed for all the experiment $(r=0.75)^{4}$. Within each stage, the value of the fragmentation measure $n$ is fixed. We used three values. In each session, we followed an ascending order of the fragmentation measure $n=1, n=2$ and $n=4$. In the case of treatment $\mathrm{B}$, we followed a descending order of the degree of publicity $P=1, P=0.50$ and $P=0.25$ (for a detailed overview of treatments, see Table 3).

Table 2: Parameters and notation

\begin{tabular}{|c|c|}
\hline$r$ (the coordination motive) & 0.75 \\
\hline$\theta$ (the true state) & {$[50,950]$} \\
\hline Precision of $x_{j}$ & {$[\theta-10, \theta+10]$} \\
\hline$\sigma_{\varepsilon}^{2}$ & 33.3333 \\
\hline Precision of $y / z_{i}$ & {$[\theta-10, \theta+10]$} \\
\hline$\sigma_{\eta}^{2}$ & 33.333 \\
\hline$u_{0}$ & 40 \\
\hline$N$ & 8 \\
\hline$P=\frac{m}{N}$ & \multicolumn{1}{c|}{ Fragmentation measure } \\
\hline$n$ & $\begin{array}{l}\text { Morris and Shin (2002): 1 public(common) signal }+1 \text { pri- } \\
\text { vate signal/ per player }\end{array}$ \\
\hline $\mathrm{MS}$ & $\begin{array}{l}\text { Partial publicity (Cornand and Heinemann }(2008)): 1 \text { pub- } \\
\text { lic signal to } P \text { players }+1 \text { private signal per player }\end{array}$ \\
\hline $\mathrm{CH}$ & $\begin{array}{l}\text { Fragmentation : 1 common signal per } 1 / n \text { of the } 8 \text { players } \\
+1 \text { private signal per player }\end{array}$ \\
\hline $\mathrm{T}$ & \multicolumn{1}{|c|}{} \\
\hline
\end{tabular}

The order of stages in both treatments is chosen as we want subjects to overreact first to public information in the first place to analyse how much they adjust to communication strategies (either partial publicity or fragmentation $)^{5}$. Moreover, we had 8 subjects per group playing together allowing to deal with $\mathrm{CH}$ and Ttreatments, respectively ${ }^{6}$.

Table 3: Experiment parameters values

\begin{tabular}{|c|c|c|c|c|c|c|c|c|c|}
\hline Sessions & Groups & Treatment & Stages & \# Periods & $r$ & $\eta_{i}$ & $\varepsilon_{j}^{i}$ & $n$ & $P$ \\
\hline \multirow{3}{*}{$1-3$} & \multirow{3}{*}{$1-6$} & \multirow{3}{*}{ A } & 1- MS & 15 & 0.75 & 10 & 10 & 1 & \\
\hline & & & 2- T1 & 15 & 0.75 & 10 & 10 & 2 & \\
\hline & & & 3- T2 & 15 & 0.75 & 10 & 10 & 4 & \\
\hline \multirow{3}{*}{$4-6$} & \multirow{3}{*}{$7-12$} & \multirow{3}{*}{ B } & 1- MS & 15 & 0.75 & 10 & 10 & & $1(8)$ \\
\hline & & & 2- CH1 & 15 & 0.75 & 10 & 10 & & $0.5(4)$ \\
\hline & & & 3- $\mathrm{CH} 2$ & 15 & 0.75 & 10 & 10 & & $0.25(2)$ \\
\hline \multicolumn{3}{|c|}{ tal of players } & \multicolumn{7}{|c|}{$96=6^{*} 16$} \\
\hline
\end{tabular}

\subsection{Adjustment of the theoretical models in the experimental setup}

We present in what follows an adjustment of the theoretical setup so that the experiment will be based on those theoretical models (Morris and Shin (2002), Cornand and Heinemann (2008) and Trabelsi (2012)) and we also proceed to determine the expressions of the corresponding expected utility (or the gain) that we need later to calculate the theoretical payoff (cf. Appendix D for fixed values used) and compare them whith those realized in the experiment.

\footnotetext{
${ }^{4}$ In a previous experiment by Cornand and Heinemann (2013) measuring the overreaction for agents according to different values of $r$, subjects tend to put larger weight on the public signal.

${ }^{5}$ We don't need, then, to test for order treatments in this case.

${ }^{6}$ Examples of screen layout are available in appendix $\mathrm{C}$.
} 


\subsubsection{Private and public information: The case of Morris and Shin (2002)}

In MS-treatment, subjects receive one public signal and a private signal that deviate from $\theta$ by some noise. Both signals have a uniform distribution, such that $y \mapsto U[\theta \pm \eta]$ and $x_{j} \mapsto U[\theta \pm \varepsilon]$.

The action of each subject $j$ on equilibrium is given by :

$$
a_{j}=\underbrace{\frac{\varepsilon}{\varepsilon+(1-r) \eta}}_{\lambda} y+\underbrace{\frac{(1-r) \eta}{\varepsilon+(1-r) \eta}}_{1-\lambda} x_{j}
$$

The average action accross all agents: $\bar{a}=\underbrace{\frac{\varepsilon}{\varepsilon+(1-r) \eta}}_{\bar{\lambda}} y+\underbrace{\frac{(1-r) \eta}{\varepsilon+(1-r) \eta}}_{1-\bar{\lambda}} \bar{x}$

Now we derive the expected utility for player $j$ according to (8) (We assume $\bar{x} \rightarrow \theta$ )

$$
\begin{gathered}
E\left(U_{j}\left(a_{j}, \theta\right)\right)=E\left[-(1-r)\left(a_{j}-\theta\right)^{2}-r\left(a_{j}-\bar{a}_{-j}\right)^{2}\right] \\
E\left(U_{j}\left(a_{j}, \theta\right)\right)=E\left[-(1-r)(\lambda(\theta+\eta)+(1-\lambda)(\theta+\varepsilon)-\theta)^{2}-r(\lambda(\theta+\eta)+(1-\lambda)(\theta+\varepsilon)-\lambda(\theta+\eta)-(1-\lambda) \theta)^{2}\right] \\
E\left(U_{j}\left(a_{j}, \theta\right)\right)=E\left(-(1-r)\left(\lambda^{2} \sigma_{\eta}^{2}\right)+(1-\lambda)^{2} \sigma_{\varepsilon}^{2}-r(1-\lambda)^{2} \sigma_{\varepsilon}^{2}\right)=-(1-r) \lambda^{2} \sigma_{\eta}^{2}-(1-\lambda)^{2} \sigma_{\varepsilon}^{2}
\end{gathered}
$$

\subsubsection{Private and P-common beliefs: The case of Cornand and Heinemann (2008)}

In CH-treatment, subjects receive two types of signals on unknown value of $\theta$ that are uniformly distributed such as in MS-treatment with the difference that $y$ will be revealed to only a proportion $P=\frac{m}{N}$ of subjects. $m$ is the number of subjects who receive the common signal $y$ and $N$ is the total number of subjects.

The optimal action of each subject is given by:

$$
a_{j}=\left\{\begin{array}{lll}
\underbrace{\frac{\varepsilon}{\varepsilon+\left(1-r \frac{m-1}{N-1}\right) \eta} y+\underbrace{\frac{\left(1-r \frac{m-1}{N-1}\right) \eta}{\varepsilon+\left(1-r \frac{m-1}{N-1}\right) \eta}}_{1-\lambda} x_{j}}_{\lambda} \quad j \in[1, m] \\
x_{j} & j \in[m+1, N]
\end{array}\right.
$$

The average action across all subjects is given by :

$$
\bar{a}=\underbrace{\frac{\frac{m}{N} \varepsilon}{\varepsilon+\left(1-r \frac{m-1}{N-1}\right) \eta}}_{\bar{\lambda}} y+\underbrace{\frac{\frac{N-m}{N-1} \varepsilon+\left(1-r \frac{m-1}{N-1}\right) \eta}{\varepsilon+\left(1-r \frac{m-1}{N-1}\right) \eta}}_{1-\bar{\lambda}} \bar{x}
$$

To determine the expression of the expected utility function for subjects who receive the public signal and for those who only receive the private signal, we need to get the expression of $\bar{a}_{-j}$

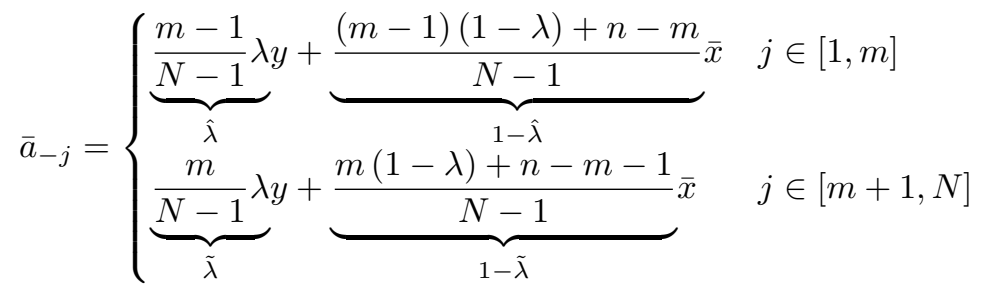

The expected utility function for a subject who gets the public signal (We assume $\bar{x} \rightarrow \theta$ ):

$$
\begin{aligned}
& E\left(U_{j}\left(a_{j}, \theta\right)\right)=E\left[-(1-r)\left(a_{j}-\theta\right)^{2}-r\left(a_{j}-\bar{a}_{-j}\right)^{2}\right] \\
& E\left(U_{j}\left(a_{j}, \theta\right)\right)=E\left[-(1-r)(\lambda(\theta+\eta)+(1-\lambda)(\theta+\varepsilon)-\theta)^{2}-r(\lambda(\theta+\eta)+(1-\lambda)(\theta+\varepsilon)-\hat{\lambda}(\theta+\eta)+(1-\hat{\lambda}) \theta)^{2}\right] \\
& E\left(U_{j}\left(a_{j}, \theta\right)\right)=\left[-(1-r) \lambda^{2}-r(\lambda-\hat{\lambda})^{2}\right] \sigma_{\eta}^{2}-(1-\lambda)^{2} \sigma_{\varepsilon}^{2}
\end{aligned}
$$


The expected utility function for a subject who only receives a private signal (We assume $\bar{x} \rightarrow \theta$ ): $E\left(U_{j}\left(a_{j}, \theta\right)\right)=E\left[-(1-r)\left(a_{j}-\theta\right)^{2}-r\left(a_{j}-\bar{a}_{-j}\right)^{2}\right]$

$E\left(U_{j}\left(a_{j}, \theta\right)\right)=E\left[-(1-r)(\theta+\varepsilon-\theta)^{2}-r(\theta+\varepsilon-\tilde{\lambda}(\theta+\varepsilon)-(1-\tilde{\lambda}) \theta)^{2}\right]$

$E\left(U_{j}\left(a_{j}, \theta\right)\right)=-\sigma_{\varepsilon}^{2}-r \tilde{\lambda}^{2} \sigma_{\eta}^{2}$

Aggregating overall subjects:

$E\left(U_{j}\left(a_{j}, \theta\right)\right)=\left(-\frac{m}{N}(1-\lambda)^{2}-\frac{N-m}{N}\right) \sigma_{\varepsilon}^{2}+\left(-\frac{m}{N}(1-r) \lambda^{2}-\frac{m}{N} r(\lambda-\hat{\lambda})^{2}-\frac{N-m}{N} \hat{\lambda}^{2}\right) \sigma_{\eta}^{2}$

Note that when $m=N$, we get exactly the expected utility function of MS-treatment.

\subsubsection{Private and semi-public information: The case of Trabelsi (2012)}

In T-treatment, there are $n$ semi-public information, observed each by $\frac{N}{n}$ subjects: $z_{i} \mapsto U\left[\theta \pm \eta_{i}\right]$. Each subject $j$ receives, in addition, his proper signal $x_{j}^{i}$.

The optimal action at equilibrium is given by:

$$
a_{j}^{i}=\underbrace{\frac{\varepsilon}{\varepsilon+\left(1-r \frac{N}{n}-1\right.} \frac{N-1}{N-1} \eta_{i}}_{\lambda} z_{i}+\underbrace{\frac{\left(1-r \frac{\frac{N}{n}-1}{N-1}\right) \eta_{i}}{\varepsilon+\left(1-r \frac{\frac{N}{n}-1}{N-1}\right) \eta_{i}}}_{1-\lambda} x_{j}^{i}
$$

The average action except $j: \bar{a}_{-j}=\lambda\left(\frac{\frac{N}{n}}{N-1} \sum_{k \neq i} z_{k}+\frac{\frac{N}{n}-1}{N-1} z_{i}\right)+(1-\lambda) \bar{x}$

The expected utility function for subject $j$ that belongs to a group $i$ (We assume $\bar{x} \rightarrow \theta$ ):

$E\left(U_{j}\left(a_{j}^{i}, \theta\right)\right)=E\left[-(1-r)\left(a_{j}-\theta\right)^{2}-r\left(a_{j}-\bar{a}_{-j}\right)^{2}\right]$

$E\left(U_{j}\left(a_{j}^{i}, \theta\right)\right)=E\left[-(1-r)(\lambda(\theta+\eta)+(1-\lambda)(\theta+\varepsilon)-\theta)^{2}+-r\left(\lambda(\theta+\eta)+(1-\lambda)(\theta+\varepsilon)-\lambda\left(\frac{N}{N-1} \sum_{k \neq i}\left(\theta+\eta_{k}\right)+\frac{\frac{N}{n}-1}{N-1}\left(\theta+\eta_{i}\right)\right)+(1-\lambda) \theta\right)\right]$

$E\left(U_{j}\left(a_{j}^{i}, \theta\right)\right)=\left[-(1-r) \lambda^{2}-r\left(\lambda^{\prime 2}+\lambda *^{2}(n-1)\right)\right] \sigma_{\eta}^{2}-(1-\lambda)^{2} \sigma_{\varepsilon}^{2}$

Where $\lambda^{\prime}=\lambda \frac{N-\frac{N}{n}}{N-1}$ and $\lambda^{*}=\lambda \frac{\frac{N}{n}}{N-1}$

Note that when $n=1$, we get the same expression of the expected utility function of MS-treatment.

\subsection{Procedural considerations}

The experiment was carried at the Groupe d'Analyse et de Théorie Economique (GATE-LSE) laboratory in Lyon (France). The experiment was computerized using Z-tree software (Fishbacher, 2007). The 96 subjects who participated in this experiment were split into 12 groups $(M=12)$. Three sessions were devoted to each treatment, producing a total of six independent observations per treatment. Most of the subjects were students. Sessions lasted about one hour, and subjects 'average earnings were about $12 €$. In each period, subjects have to make a decision on the true state given the signals. For the action choice, subjects were paid according to the payoff function in (7), which was exchanged to the rate of 1000 ECU (Experimental Currency Unit) $=1 €$. Instructions, given in detail in the appendices, were distributed in a written form to subjects and were read out loud before the beginning of each session. It was made sure that these instructions were well understood. Subjects were asked to raise their hands if they had any questions, and answers were given privately by the experimenter ${ }^{7}$.

\section{Results and discussion}

\subsection{Some descriptive statistics}

First of all, we derive the theoretical predictions relative to the weights attached to the public and semi-public information. The column $E_{j}^{i}(\theta)$ of Table 4 corresponds to the weight assigned to the public or the semipublic (either partially disclosed or fragmented) according to the best linear expectation of the true state. The

\footnotetext{
${ }^{7}$ We allowed subjects to move a cursor only inside the interval defined by the signals to determine the action. This fact restrains subjects from choosing actions outside of their signal interval.
} 
corresponding weights in MS and T stages are given by the following formula: $\frac{\varepsilon}{\varepsilon+\eta}$. In CH-stages, the weight becomes $P \frac{\varepsilon}{\varepsilon+\eta}$. $\lambda$ shows the equilibrium weight in the rational behavior for subjects who get the public or the semi-public information, and $\bar{\lambda}$ shows the optimal equilibrium over all subjects.

We begin by conducting some descriptive analyses that explore the weight assigned to the public (or semipublic) signal by the subjects in the experiment depending on the treatment. In order to calculate the weights, we proceed as follows: For each treatment and for each group, we caculate the weight on public information using this formula ${ }^{8}$ :

$$
w_{j, t}=\frac{\left|a_{j, t}-x_{j, t}\right|}{\left|y_{j, t}-x_{j, t}\right|}
$$

where $j=1,2, \ldots .8$ and $t=1,2, \ldots, 15$

Table 4: Theoretical predictions

\begin{tabular}{|c|c|c|c|c|c|c|c|c|c|}
\hline & Stages & $r$ & $\varepsilon_{j}^{i}$ & $\eta_{i}$ & $P$ & $n$ & $E_{j}^{i}(\theta)$ & $\lambda$ & $\bar{\lambda}$ \\
\hline \hline \multirow{3}{*}{ Groups 1-6 } & $1-\mathrm{MS}$ & 0.75 & 10 & 10 & & 1 & 0.5 & 0.8 & 0.8 \\
\cline { 2 - 10 } & $2-\mathrm{T} 1$ & 0.75 & 10 & 10 & & 2 & 0.5 & 0.5957 & 0.5957 \\
\cline { 2 - 10 } & $3-\mathrm{T} 2$ & 0.75 & 10 & 10 & & 4 & 0.5 & 0.5283 & 0.5283 \\
\hline \multirow{3}{*}{ Groups 7-12 } & $1-\mathrm{MS}$ & 0.75 & 10 & 10 & $1(8)$ & & 0.5 & 0.8 & 0.8 \\
\cline { 2 - 10 } & $2-\mathrm{CH} 1$ & 0.75 & 10 & 10 & $0.50(4)$ & & 0.25 & 0.5957 & 0.2978 \\
\cline { 2 - 9 } & $3-\mathrm{CH} 2$ & 0.75 & 10 & 10 & $0.25(2)$ & & 0.125 & 0.5283 & 0.1321 \\
\hline
\end{tabular}

The final observed weights are averaged over subjects and over periods: $\overline{\bar{w}}=\frac{1}{15} \frac{1}{8} \sum_{t=1}^{15} \sum_{j=1}^{8} w_{j, t}$. Descriptive statistics shown in Table 5 provide some initial evidence that subjects tend to overreact -though not so strong- to public signal, especially in MS-treatment. The weights decrease in partial transparent treatments as predicted in theory.

Table 5: Observed and theoretical average weight on the public/semi public signal

(a) Observed and theoretical average weight on the public/semi public signal for groups 1-6

\begin{tabular}{|c|c|c|c|c|}
\hline Session & Group & MS & T1 & T2 \\
\hline \hline 1 & 1 & 0.570608378 & 0.547902395 & 0.469587499 \\
\hline 1 & 2 & 0.60279939 & 0.511131085 & 0.555996466 \\
\hline 2 & 3 & 0.561053942 & 0.554082587 & 0.507770622 \\
\hline 2 & 4 & 0.57195844 & 0.652339574 & 0.537511011 \\
\hline 3 & 5 & 0.535828025 & 0.583791449 & 0.529230798 \\
\hline 3 & 6 & 0.612962297 & 0.552269316 & 0.493752244 \\
\hline \multicolumn{2}{|c|}{ Average group } & 0.575868412 & 0.566919401 & 0.51564144 \\
\hline \multicolumn{2}{|r|}{ Theoretical weight } & 0.8 & 0.5957 & 0.5283 \\
\hline
\end{tabular}

(b) Observed and theoretical average weight on the public/semi public signal for groups 7-12

\begin{tabular}{|c|c|c|c|c|c|c|}
\hline Session & Group & MS & CH1inf & CH1 & CH2inf & CH2 \\
\hline \hline 4 & 7 & 0.522276562 & 0.48319534 & 0.240936224 & 0.460659283 & 0.117219109 \\
\hline 4 & 8 & 0.514370821 & 0.49636507 & 0.248182535 & 0.525562698 & 0.132572743 \\
\hline 5 & 9 & 0.611633298 & 0.491836658 & 0.249750691 & 0.492093677 & 0.124004759 \\
\hline 5 & 10 & 0.533378693 & 0.489211049 & 0.244605524 & 0.478262819 & 0.119565705 \\
\hline 6 & 11 & 0.49185319 & 0.540945281 & 0.274704153 & 0.512655031 & 0.128163758 \\
\hline 6 & 12 & 0.489843976 & 0.488669775 & 0.237979233 & 0.456122975 & 0.109818575 \\
\hline \multicolumn{2}{|r|}{ Average group } & 0.52722609 & 0.498370529 & 0.249359727 & 0.487559414 & 0.121890775 \\
\hline \multicolumn{2}{|r|}{ Theoretical weight } & 0.8 & 0.5957 & 0.29787234 & 0.5283 & 0.132075472 \\
\hline
\end{tabular}

\footnotetext{
${ }^{8}$ We followed Cornand and Baeriswyl (2013).
} 
The weight assigned to the public (or semi-public) signal is significantly lower than the theoretical value in MS-treatment for all groups $1-12$ with a p-value $=0.0277$. In T-treatments, the hypothesis cannot be rejected (p-values $=0.2489$ for T1 and 0.4631 for T2)). While rejection is found for groups 7-12 in CH-treatments with the corresponding $\mathrm{p}$-values $=0.0277$ and 0.0464 . The average weight assigned to the public/semi-public signal as well as its variance which are aggregated this time by period are also reported in Figure 1 and Figure 3, respectively. We see clearly that average observed weights are close to the theoretical values in the case of $\mathrm{T} 1$, T2, while this is not the case for MS, CH1 and CH2 stages, resp. A visual inspection of Figure 2, which plots the average weight assigned by each group in each treatment in each of the 15 periods, shows a much larger weight in MS-treatment compared to CH-treatments, while the weights in MS, T1 and T2 are close to each one.

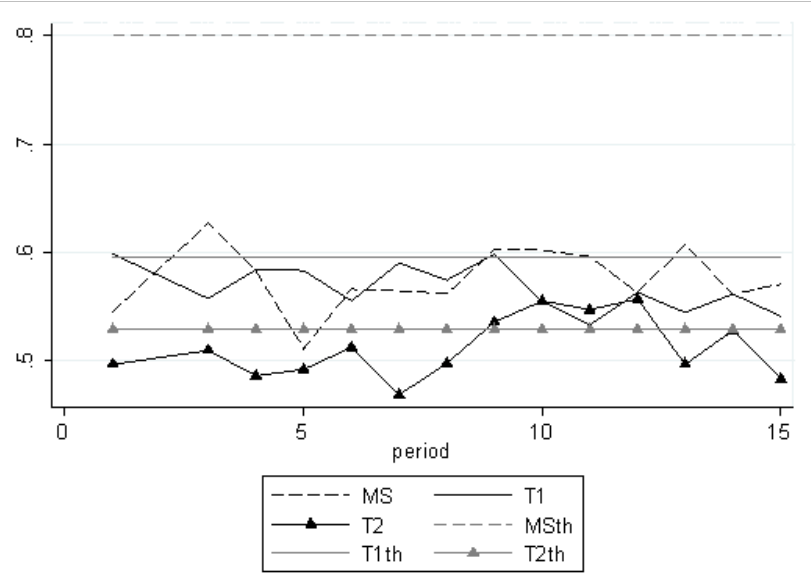

(a) Average weight assigned to public/semi-public signal for Treatment A (1-6)

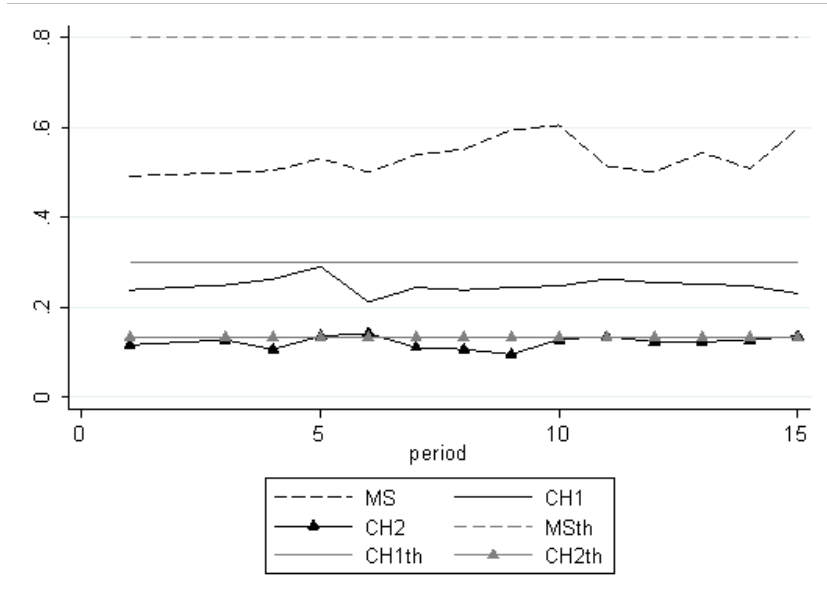

(b) Average weight assigned to public/semi-public signal for Treatment B (7-12)

Figure 1: Average weight assigned to public/semi-public signal for Treatment A and B, th: refers to "theoretical"

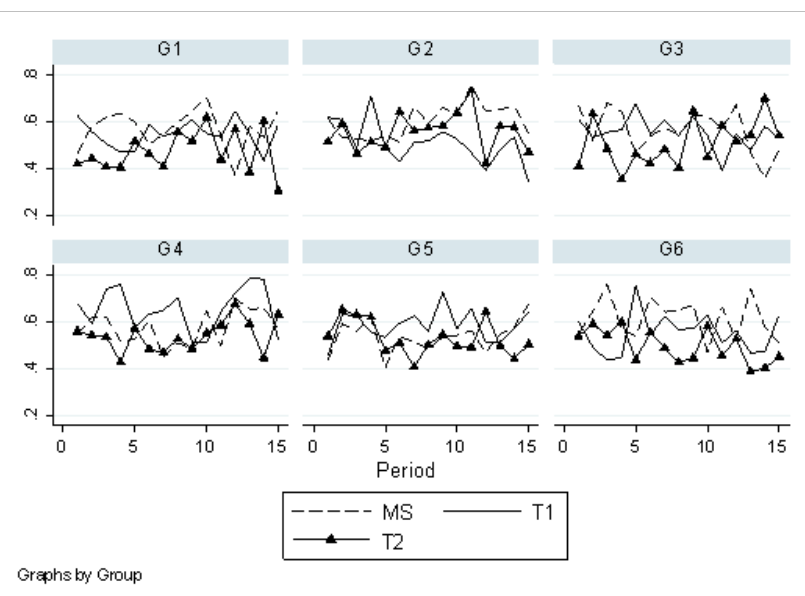

(a) Average weight assigned to the public/semi-public signal for groups 1-6

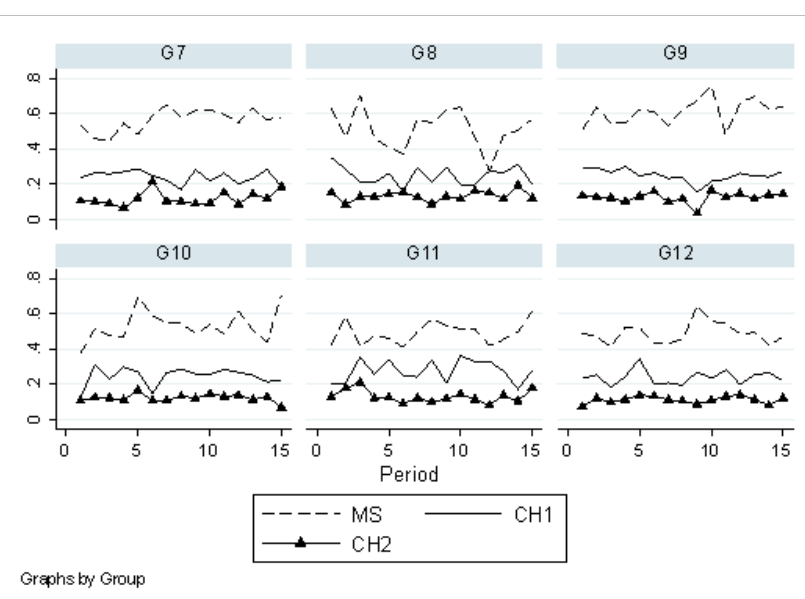

(b) Average weight assigned to the public/semi-public signal for groups $7-12$

Figure 2: Average weight assigned to the public/semi-public signal for groups 1-12

We can state our first result as follows:

\section{Result 1.}


- In MS-treatment (1-12): the weight assigned to the public signal is significantly lower than its theoretical value.

- In T-treatments (1-6): the weight that subjects in the experiment attach to the semi-public signal is not significantly different from theoretical values.

- In CH-treatments (7-12): the weight is significantly lower than the theoretical value.

- In CH-informed (7-12), the weight is significantly lower than the theoretical value.
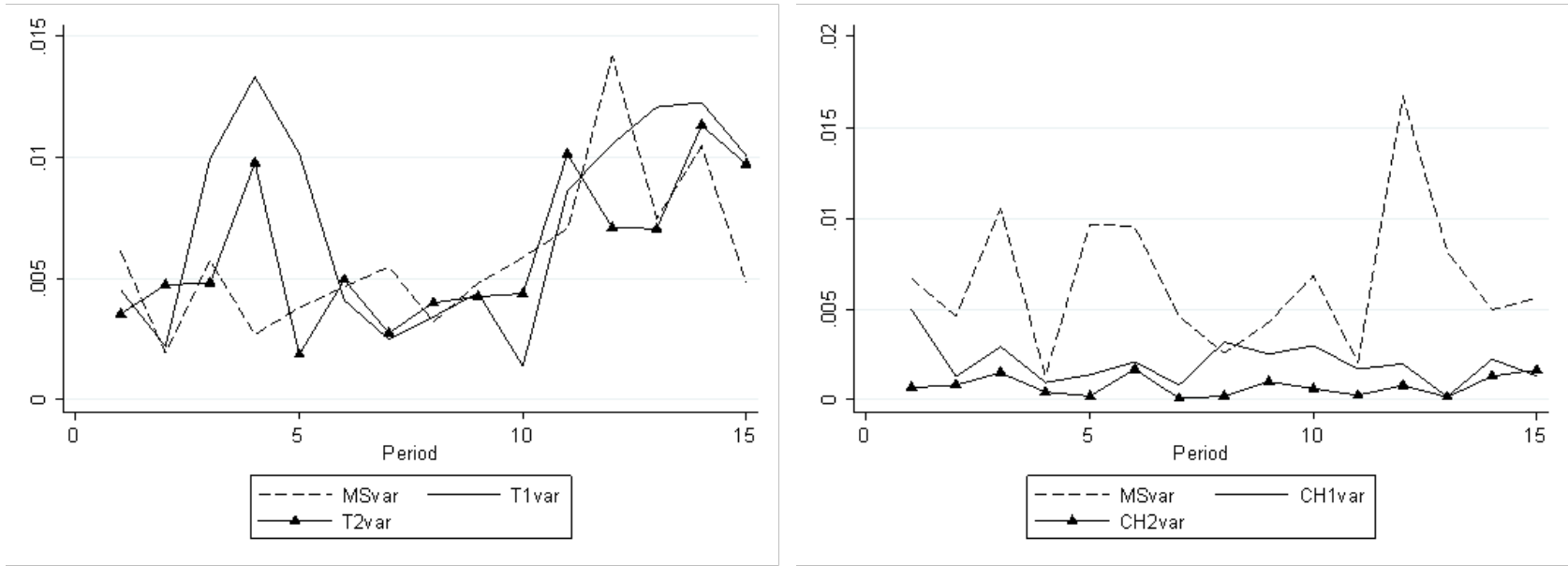

(a) Average variance of weights on public/semi-public signal for (b) Average variance of weights on public/semi-public signal for Treatment A Treatment B

Figure 3: Average variance of weights on public/semi-public signal for Treatments A and B

The realized along with the theoretical average payoff are reported in the last lines of Table 6 (aggregated by group) and on the Figures 4 and 5 (aggregated by period and by group, respectively). 
Table 6: Observed and theoretical payoff for groups 1-12

(a) Observed and theoretical average payoff for groups 1-6

\begin{tabular}{|c|c|c|c|c|}
\hline Session & Group & MS & T1 & T2 \\
\hline \hline 1 & 1 & 276.813532 & 236.7903507 & 222.8636113 \\
\hline 1 & 2 & 275.296778 & 207.024131 & 219.3019022 \\
\hline 2 & 3 & 293.37568 & 213.57185 & 191.644543 \\
\hline 2 & 4 & 284.8567 & 237.768111 & 243.785683 \\
\hline 3 & 5 & 282.743724 & 199.367896 & 216.131322 \\
\hline 3 & 6 & 284.014721 & 199.4099 & 201.445044 \\
\hline \multicolumn{2}{|r|}{ Average group } & 282.8501892 & 215.6553731 & 215.8620176 \\
\hline \multicolumn{2}{|r|}{ Theoretical payoff } & 333.3333333 & 258.0051305 & 234.2233298 \\
\hline
\end{tabular}

(b) Observed and theoretical average payoff for groups 7-12

\begin{tabular}{|c|c|c|c|c|c|c|}
\hline Session & Group & MS & CH1 & CH1inf & CH2 & CH2inf \\
\hline \hline 4 & 7 & 188.419453 & 212.99358 & 261.335785 & 166.242015 & 183.859628 \\
\hline 4 & 8 & 201.679532 & 209.168734 & 272.13497 & 167.421375 & 210.447564 \\
\hline 5 & 9 & 209.929538 & 215.818793 & 27171487 & 163.868895 & 230.68721 \\
\hline 5 & 10 & 191.498937 & 199.235248 & 232.905324 & 186.449527 & 247.098987 \\
\hline 6 & 11 & 241.724278 & 196.297724 & 251.040025 & 182.696148 & 228.5519903 \\
\hline 6 & 12 & 233.105939 & 218.758784 & 285.022702 & 153.648478 & 228.4519133 \\
\hline \multicolumn{2}{|c|}{ Average group } & 211.0596128 & 208.07121438 & 262.358946 & $170, .0544063$ & 221.5162154 \\
\hline \multicolumn{2}{|r|}{ Theoretical payoff } & 333.3333333 & 165.9574468 & 286.9775162 & 111.5917092 & 254.1196946 \\
\hline
\end{tabular}

Recall that in order to caculate the theoretical payoff, we need to replace each parameter by its value in the expected utility expression corresponding to each case (MS, T and $\mathrm{CH}$ ) according to Table 3 and then multiplied by 10, the payoffs are significantly lower than their corresponding theoretical values in most of the treatments.

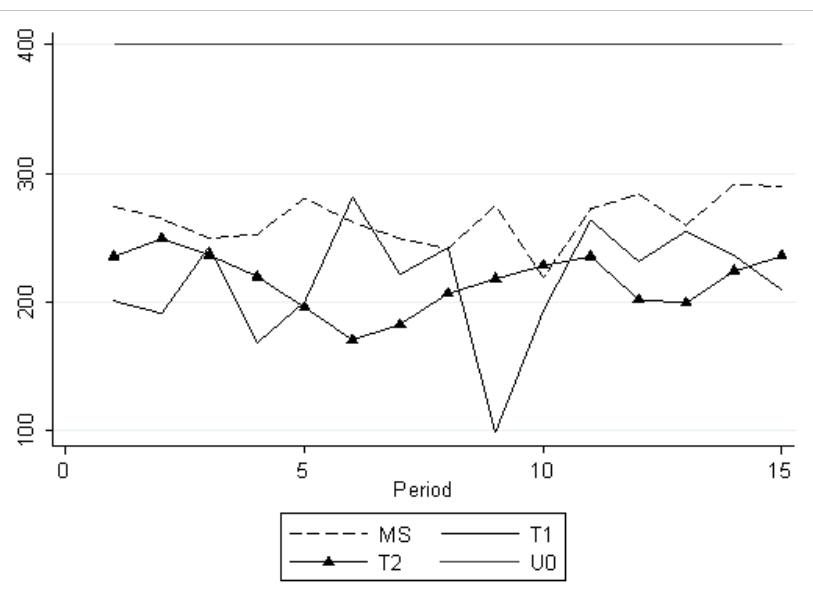

(a) Average payoff for Treatment A

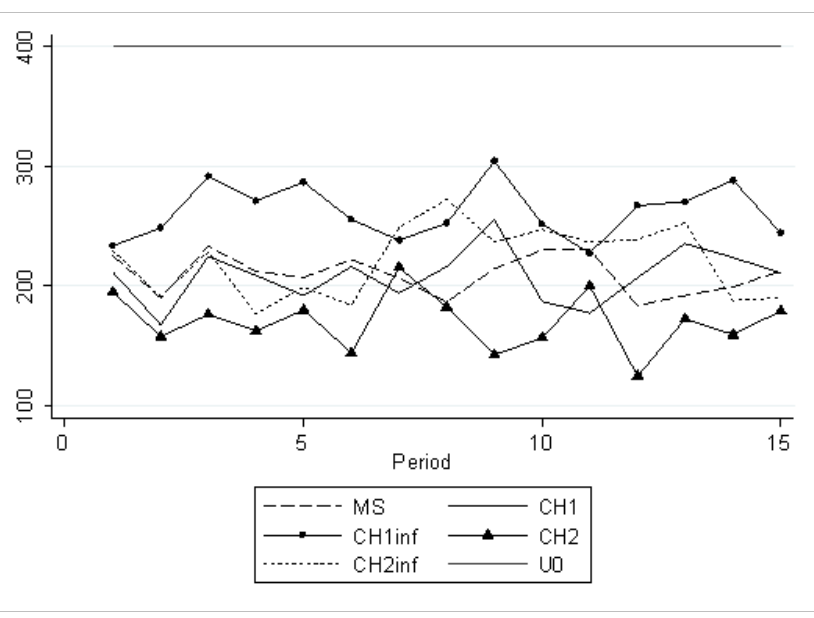

(b) Average payoff for Treatment B

Figure 4: Average payoff for Treatments A and B 


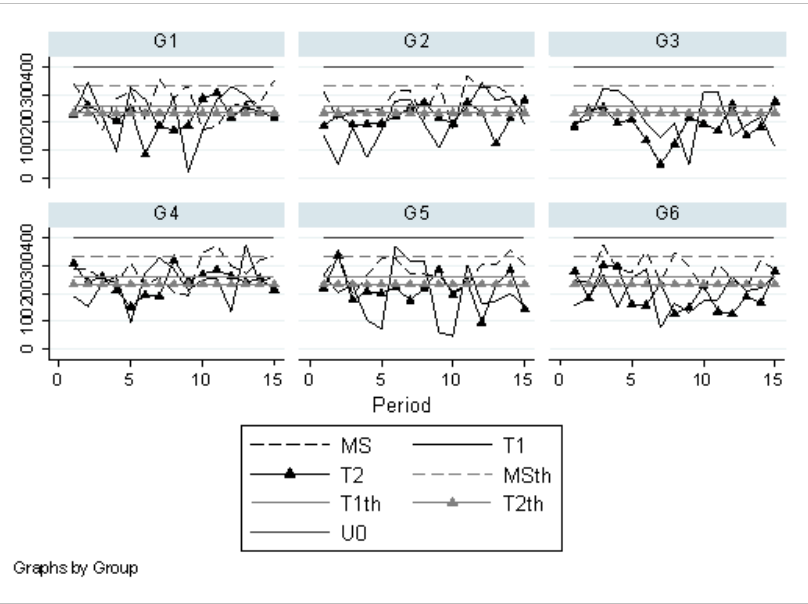

(a) Average payoff for groups 1-6

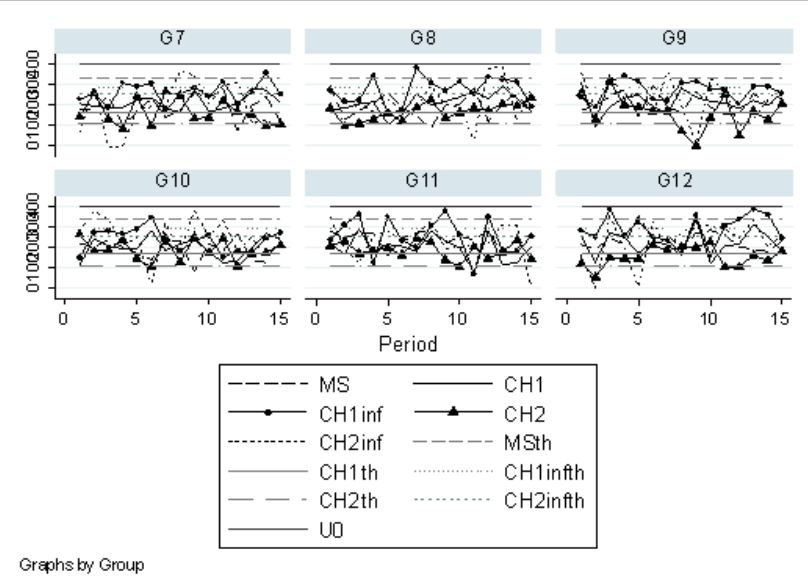

(b) Average payoff for groups 7-12

Figure 5: Average payoff for groups 1-12

\subsection{Overreaction issue: comparison between theoretical predictions and experi- mental results}

The hypothesis to be tested in this case is: $H_{0}$ : the observed weight on the public (resp. semi-public) information by a group $M$ in treatment $G$ is not different from the theoretical weight in $E_{j}(\theta)$.

We perform for this purpose a non-parametric test: Wilcoxon matched pair signed rank test, which is very useful when we would like to compare observed values with fixed ones (cf. Table 7).

We find that the weight assigned in MS-treatment is significantly larger than its face value for all groups 1-12. The p-value is overwemingly below the $5 \%$ significance level. But the same result doesn't hold if we consider seperate groups. For groups 7-12, the hypothesis cannot be rejected anymore.

We can state the second result:

Result 2. For all groups, the weight assigned to public signal is larger than the one attributed in the first order expectation. Subjects do overreact to the common signal. Subjects still overreact to the semi-public information in T1-treatment. But overreaction is efficiently reduced in T2-treatment and also in CH-treatments ${ }^{9}$.

Table 7: Overreaction test results

\begin{tabular}{|c|c||c|c|}
\hline MS (1-6) & MS (1-12) & T1 (1-6) & T2 (1-6) \\
\hline \hline Reject (p-value=0.0277 & \multirow{3}{*}{ Reject (p-value=0.0047) } & Reject (p-value=0.0277) & Accept (p-value=0.2489) \\
\cline { 3 - 4 } & & CH1 (7-12) & CH2 (7-12) \\
\cline { 3 - 4 } MS (7-12) & & Accept (p-value=0.3454) & Accept (p-value=0.3454) \\
\hline Accept (p-value=0.1157) & &
\end{tabular}

\subsection{Comparison between treatments}

It is an evidence that CH-treatments differ from MS-treatments by a simple analytical comparison between respective observed weights. However, we should compare between MS and CH1inf (inf refers to "informed" subjects who receive the public signal) and CH2inf, respectively. Let us start with the statistical test conducted for groups the 1-6 only (cf. Table 8). The hypothesis to be tested is: $H_{0}$ : the observed weight on the public (resp. semi-public) information by a group $M$ in treatment $G_{1}$ is not different from the weight in treatment $G_{2}$

We conduct similarly a non-parametric test: Wilcoxon matched pair signed rank test which results in an insignificant difference between MS-treatment and T1-treatments while we can reject the same hypothesis when we compare MS-treatment with T2-treatment ( $\mathrm{p}$-value=0.0277). And finally, we reject equality between T1treatment and T2-treatment with a $\mathrm{p}$-value $=0.0464$, which seems to be a logical result. This finding corroborates

\footnotetext{
${ }^{9}$ The last finding doesn't coincide with the observations of Cornand and Baeriswyl (2013).
} 
our previous results, that is the reduction of overreaction was efficient in that last phase of the experiment for subjects of groups 1-6. Finally, there are no significant differences between weights assigned in MS, CH1inf and CH2inf.

\section{Result 3.}

- The weights assigned in the MS-treatment and T1-treatment, respectively, are significantly larger than in T2-treatment.

- The reduction of overreaction is more efficient when the fragmentation measure $n$ is sufficienlty high.

- The difference between weights assigned in the MS-treatment, CH1inf-treatment and CH2inf is insignifcant.

Table 8: Comparison between treatments results

(a) Comparison between MS and T1 and T2 stages

\begin{tabular}{|c|c|c|c|}
\hline & MS & T1 & T2 \\
\hline \hline MS & $\mathrm{X}$ & Accept $(\mathrm{p}$-value=0.6002) & Reject $(\mathrm{p}$-value=0.0277) \\
\hline \hline T1 & Accept $(\mathrm{p}$-value=0.6002) & $\mathrm{X}$ & Reject $(\mathrm{p}$-value=0.0464) \\
\hline \hline T2 & Reject $(\mathrm{p}$-value $=0.0277)$ & Reject $(\mathrm{p}$-value $=0.0464)$ & $\mathrm{X}$ \\
\hline
\end{tabular}

(b) Comparison between MS and CH1inf and CH2inf stages

\begin{tabular}{|c|c|c|c|}
\hline & MS & CH1inf & CH2inf \\
\hline \hline MS & $\mathrm{X}$ & Accept $(\mathrm{p}$-value=0.2489) & Accept $(\mathrm{p}$-value=0.1159) \\
\hline \hline CH1inf & Accept $(\mathrm{p}$-value=0.2489) & $\mathrm{X}$ & Accept $(\mathrm{p}$-value=0.3454) \\
\hline \hline CH2inf & Accept $(\mathrm{p}$-value $=0.1159)$ & Accept $(\mathrm{p}$-value=0.3454) & $\mathrm{X}$ \\
\hline
\end{tabular}

\subsection{Predictive power of K-level reasoning}

In k-level thinking models, players have different levels of strategic sophistication, hence behave heterogeneously. When a subject doesn't choose an equilibrium action, this means that he follows a limited level of thinking. The models of limited depth of reasoning are introduced by Stahl and Wilson (1994) and Nagel (1995) and are successful at accounting for systematic deviation from equilibrium behavior.

Within the setting introduced in section 2, we derive actions that correspond to different levels of reasoning. is:

Player $j$ chooses $a_{j}$ to maximize (1) (The utility function) and from the first order condition, the best response

$$
a_{j}=(1-r) E_{j}(\theta)+r E_{j}\left(\bar{a}_{-j}\right)
$$

We define level 0 in which agent is non strategic and randomly choose a number between two signals. Level $1\left(L_{1}\right)$ player expects that other players are $L_{0}$ players. It means that $L_{1}$ player believes that average action of other players will be equal to their own estimated state, and so on...In this section, we propose to derive weights put on public, and semi-public information.

\subsubsection{Private and public information: The case of Morris and Shin (2002)}

Suppose that all players except player $j$ atttach weight $\tau_{k}{ }^{10}$ to the public signal. The best response of player $j$ to such behavior is :

$$
a_{j}(k+1)=(1-r) E_{j}(\theta)+r E_{j}\left(\bar{a}_{-j}\right)
$$

\footnotetext{
${ }^{10} \tau_{0}$ corresponds to the weight given by the first order-expectation in $E_{j}(\theta)$
} 


$$
a_{j}(k+1)=(1-r) E_{j}(\theta)++r\left[\tau_{k} y+\left(1-\tau_{k}\right) E_{j}(\theta)\right]
$$

We replace $E_{j}(\theta)$ by its expression $\left(\frac{\varepsilon}{\varepsilon+\eta} y+\frac{\eta}{\varepsilon+\eta} x_{j}\right)$ and rearranging terms, we get:

$$
a_{j}(k+1)=\underbrace{\left[\left(1-r \tau_{k}\right) \frac{\varepsilon}{\varepsilon+\eta}+r \tau_{k}\right]}_{\tau_{k+1}} y+\underbrace{\left[\left(1-r \tau_{k}\right) \frac{\eta}{\varepsilon+\eta}\right]}_{1-\tau_{k+1}} x_{j}
$$

By replacing $\varepsilon, \eta$, and $r$ by their fixed values in the experiment, we get the following weights for the level of reasoning:

\begin{tabular}{|c|c|}
\hline Treatment A/B & Stage 1 \\
\hline \hline$\tau_{0}$ & 0.5 \\
\hline$\tau_{1}$ & 0.6875 \\
\hline$\tau_{2}$ & 0.7578 \\
\hline$\tau_{3}$ & 0.7842 \\
\hline$\tau_{\infty}$ & 0.8 \\
\hline
\end{tabular}

\subsubsection{Private and P-common beliefs: The case of Cornand and Heinemann (2008)}

For subjects who only receive the private signal, they have no choice but playing $a_{j}=x_{j}$.

For subjects who receive both signals:

$$
\begin{gathered}
a_{j}(k+1)=(1-r) E_{j}(\theta)+r E_{j}\left(\bar{a}_{-j}\right) \\
a_{j}(k+1)=(1-r) E_{j}(\theta)++r\left[\frac{m-1}{N-1}\left(\tau_{k} y+\left(1-\tau_{k}\right) E_{j}(\theta)\right)+\frac{N-m}{N-1} E_{j}(\theta)\right]
\end{gathered}
$$

We replace $E_{j}(\theta)$ by its expression $\left(\frac{\varepsilon}{\varepsilon+\eta} y+\frac{\eta}{\varepsilon+\eta} x_{j}\right)$ and rearranging terms, we get:

$$
a_{j}(k+1)=\underbrace{\frac{(N-1) \varepsilon+(m-1) r \tau_{k} \eta}{(N-1)(\varepsilon+\eta)}}_{\tau_{k+1}} y+\underbrace{\frac{\left(N-1-(m-1) \tau_{k}\right) \eta}{(N-1)(\varepsilon+\eta)}}_{1-\tau_{k+1}} x_{j}
$$

Averaging over all agents,

$$
\bar{a}_{j}(k+1)=\underbrace{\frac{m\left((N-1) \varepsilon+(m-1) r \tau_{k} \eta\right)}{N(N-1)(\varepsilon+\eta)}}_{\bar{\tau}_{k+1}} y+\underbrace{\frac{(N-m)+m\left((N-1)-(m-1) \tau_{k}\right) \eta}{N(N-1)(\varepsilon+\eta)}}_{1-\bar{\tau}_{k+1}} \bar{x}
$$

By replacing $N, m, \varepsilon, \eta$, and $r$ by their fixed values in the experiment, we get the following weights for the level of reasoning:

\begin{tabular}{|c|c|c|}
\hline Treatment B & Stage 2 & Stage 3 \\
\hline \hline$\tau_{0}$ & 0.25 & 0.125 \\
\hline$\tau_{1}$ & 0.2901 & 0.1316 \\
\hline$\tau_{2}$ & 0.2966 & 0.1320 \\
\hline$\tau_{3}$ & 0.2976 & 0.1321 \\
\hline$\tau_{\infty}$ & 0.2978 & 0.1321 \\
\hline
\end{tabular}




\subsubsection{Private and semi-public information: The case of Trabelsi (2012)}

All players (except $j$ ) attach weight $\tau_{k}$ to the semi-public signal. The best response will be :

$$
\begin{gathered}
a_{j}^{i}(k+1)=(1-r) E_{j}^{i}(\theta)+r E_{j}^{i}\left(\bar{a}_{-j}\right) \\
a_{j}^{i}(k+1)=(1-r) E_{j}^{i}(\theta)+r\left[\tau_{k}\left(\frac{N-\frac{N}{n}}{N-1} E_{j}^{i}(\theta)+\frac{\frac{N}{n}-1}{N-1} z_{i}\right)+\left(1-\tau_{k}\right) E_{j}^{i}(\theta)\right]
\end{gathered}
$$

We replace $E_{j}^{i}(\theta)$ by its expression $\left(\frac{\varepsilon}{\varepsilon+\eta_{i}} z_{i}+\frac{\eta}{\varepsilon+\eta_{i}} x_{j}^{i}\right)$ and rearranging terms, we get:

$$
a_{j}^{i}(k+1)=\underbrace{\frac{r \tau_{k}\left(\frac{N}{n}-1\right) \eta_{i+\varepsilon(N-1)}}{(N-1)\left(\varepsilon+\eta_{i}\right)}}_{\tau_{k}} z_{i}+\underbrace{\left(1-r \tau_{k} \frac{\frac{N}{n}-1}{N-1}\right) \frac{\varepsilon}{\varepsilon+\eta_{i}}}_{1-\tau_{k+1}} x_{j}^{i}
$$

By replacing $N, n, \varepsilon, \eta_{i}$, and $r$ by their fixed values in the experiment, we get the following weights for the level of reasoning:

\begin{tabular}{|c|c|c|}
\hline Treatment A & Stage 2 & Stage 3 \\
\hline \hline$\tau_{0}$ & 0.5 & 0.5 \\
\hline$\tau_{1}$ & 0.5803 & 0.5267 \\
\hline$\tau_{2}$ & 0.5932 & 0.5282 \\
\hline$\tau_{3}$ & 0.5953 & 0.5282 \\
\hline$\tau_{\infty}$ & 0.5957 & 0.5283 \\
\hline
\end{tabular}

Table 9 provides a summary of the theoretical weights on public or semi-public according to different levels of reasoning.

Table 9: Theoretical average weights on the public and semi-public signal according to levels of reasoning for each treatment

\begin{tabular}{|c|c|c|c|c|c|}
\hline Treatment & MS & T1 & CH1 & T2 & CH2 \\
\hline Group & $1-12$ & $1-6$ & $7-12$ & $1-6$ & $7-12$ \\
\hline \hline$L 0$ & 0.5 & 0.5 & 0.25 & 0.5 & 0.125 \\
\hline$L 1$ & 0.6875 & 0.5803 & 0.2901 & 0.5267 & 0.1316 \\
\hline$L 2$ & 0.7578 & 0.5932 & 0.2966 & 0.5282 & 0.1320 \\
\hline$L 3$ & 0.7842 & 0.5953 & 0.2976 & 0.5282 & 0.1321 \\
\hline$L_{4}$ & 0.7940 & 0.5956 & 0.2978 & 0.5283 & 0.1321 \\
\hline$L_{5}$ & 0.7941 & 0.5957 & 0.2978 & 0.5283 & 0.1321 \\
\hline$L_{6}$ & 0.7977 & 0.5957 & 0.2978 & 0.5283 & 0.1321 \\
\hline$L_{\infty}($ eq $)$ & 0.8 & 0.5957 & 0,2978 & 0.5283 & 0.1321 \\
\hline Observed weight & 0.5515 & 0.5669 & 0.2493 & 0.5156 & 0.1218 \\
\hline \multicolumn{5}{|r}{}
\end{tabular}

As we have explained, players use simplified models in order to avoid the complexity of equilibrium. The hypothesis to be tested is:

$H_{0}$ : The observed weight is not different from the value of the theoretical weight at level $k$.

Through Wilcoxon matched pair signed rank test, we can see that subjects don't have high levels of reasoning in MS-treatment (Table 10). On average, subjects' weights are located between $L_{0}$ and $L_{1}$ (See Figure 6). The hypothesis cannot be rejected for levels 1 and higher in the case of T1-treatment, while it's rejected in $\mathrm{CH}-$ treatments, where the weight is significantly lower for each level $k \geq 1$. And the hypothesis is accepted for all levels in the case of T2-treatment. 
Table 10: Tests results of the hypothesis: The observed weight is not different from the the value of the theoretical weight at level $k$

(a) Results for groups 1-6

\begin{tabular}{|c|c|c|c|}
\hline Treatment & MS & T1 & T2 \\
\hline \hline Group & $1-6$ & $1-6$ & $1-6$ \\
\hline$L 0$ & Reject $(\mathrm{p}$-value $=0.0277)$ & Reject $(\mathrm{p}$-value $=0.0277)$ & Accept $(\mathrm{p}$-value $=0.2489)$ \\
\hline$L 1$ & Reject $(\mathrm{p}$-value $=0.0277)$ & Accept $(\mathrm{p}$-value $=0.4631)$ & Accept $(\mathrm{p}$-value $=0.4631)$ \\
\hline$L 2$ & Reject $(\mathrm{p}$-value $=0.0277)$ & Accept $(\mathrm{p}$-value $=0.2486)$ & Accept $(\mathrm{p}$-value $=0.4631)$ \\
\hline$L 3$ & Reject $(\mathrm{p}$-value $=0.0277$ & Accept $(\mathrm{p}$-value $=0.2486)$ & Accept $(\mathrm{p}$-value $=0.4631)$ \\
\hline$L_{4}$ & Reject $(\mathrm{p}$-value $=0.0277$ & Accept $(\mathrm{p}$-value $=0.2486)$ & Accept $(\mathrm{p}$-value $=0.4631)$ \\
\hline$L_{5}$ & Reject $(\mathrm{p}$-value $=0.0277$ & Accept $(\mathrm{p}$-value $=0.2486)$ & Accept $(\mathrm{p}$-value $=0.4631)$ \\
\hline
\end{tabular}

(b) Results for groups 7-12

\begin{tabular}{|c|c|c|c|}
\hline Treatment & MS & CH1 & CH2 \\
\hline \hline Group & $7-12$ & 7 -12 & 7 -12 \\
\hline$L 0$ & Accept $(\mathrm{p}$-value $=0.1157)$ & Accept $\mathrm{p}$-value $=0.3454)$ & Accept $(\mathrm{p}$-value $=0.3454)$ \\
\hline$L 1$ & Reject $(\mathrm{p}$-value $=0.0277)$ & Reject $\mathrm{p}$-value $=0.0277)$ & Reject $(\mathrm{p}$-value $=0.0431)$ \\
\hline$L 2$ & Reject $(\mathrm{p}$-value $=0.0277)$ & Reject $\mathrm{p}$-value $=0.0277)$ & Reject $(\mathrm{p}$-value $=0.0431)$ \\
\hline$L 3$ & Reject $(\mathrm{p}$-value $=0.0277)$ & Reject $\mathrm{p}$-value $=0.0277)$ & Reject $(\mathrm{p}$-value $=0.0431)$ \\
\hline$L_{4}$ & Reject $(\mathrm{p}$-value $=0.0277)$ & Reject $\mathrm{p}$-value $=0.0277)$ & Reject $(\mathrm{p}$-value $=0.0431)$ \\
\hline$L_{5}$ & Reject $(\mathrm{p}$-value $=0.0277)$ & Reject $\mathrm{p}$-value $=0.0277)$ & Reject $(\mathrm{p}$-value $=0.0431)$ \\
\hline
\end{tabular}

In order to strengthen our previous observations, we propose to complete with an individual analysis of subjects' behavior in the lines of Shapiro et al. (2010). We see that subjects operate different levels of reasoning depending on the treatment. According to Table 11, the number of cases in which subjects operate the same level of reasoning as in MS-treatment is higher in T2 than in T1-treatment (20 cases versus 16). This means that players attach importance to "the de-coordination effect" induced by an increase in the fragmentation measure $(n=4)$, this observation corraborates our result found in section 4.2 , where the reduction of overreaction was more efficient in T2-treatment.

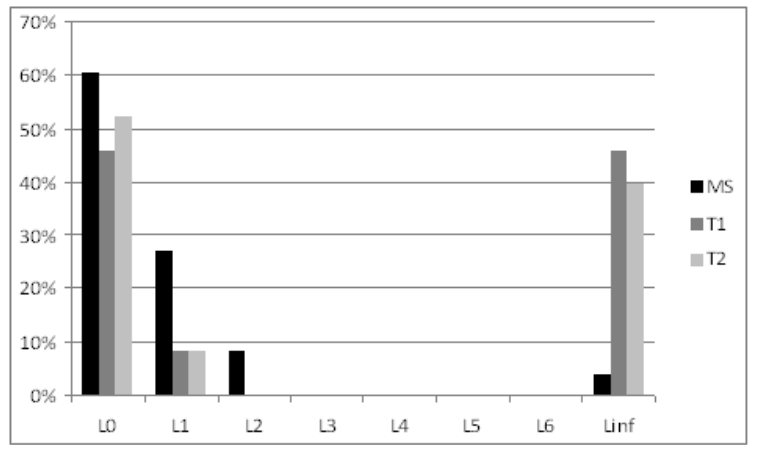

(a) Frequency of players according to levels of reasoning for groups 1-6

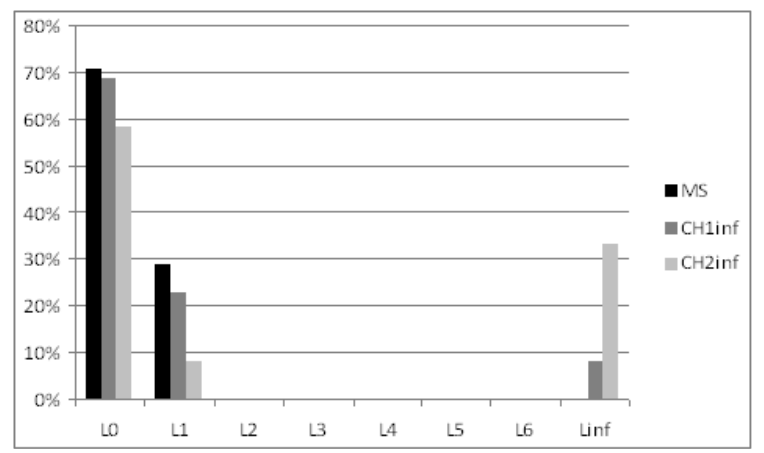

(b) Frequency of players according to levels of reasoning for groups 7-12

Figure 6: Frequency of players according to different levels of reasoning 
Table 11: Individual behavior of subjects: Groups 1-6

\begin{tabular}{|c|c|c|c|c|c|c|c|c|c|c|c|c|c|c|c|c|c|}
\hline \multicolumn{2}{|c|}{ Subjects } & 1 & 2 & 3 & 4 & 5 & 6 & 7 & 8 & 9 & 10 & 11 & 12 & 13 & 14 & 15 & 16 \\
\hline \multirow{3}{*}{ Session 1} & MS & $L_{1}$ & $L_{1}$ & $L_{0}$ & $L_{0}$ & $L_{0}$ & $L_{1}$ & $L_{0}$ & $L_{1}$ & $L_{0}$ & $L_{1}$ & $L_{1}$ & $L_{0}$ & $L_{0}$ & $L_{2}$ & $L_{0}$ & $L_{2}$ \\
\hline & $\mathrm{T} 1$ & $L_{0}$ & $L_{1}$ & $L_{0}$ & $L_{0}$ & $L_{\infty}$ & $L_{\infty}$ & $L_{1}$ & $L_{0}$ & $L_{\infty}$ & $L_{\infty}$ & $L_{0}$ & $L_{0}$ & $L_{0}$ & $L_{1}$ & $L_{0}$ & $L_{1}$ \\
\hline & $\mathrm{T} 2$ & $L_{\infty}$ & $L_{1}$ & $L_{0}$ & $L_{0}$ & $L_{0}$ & $L_{0}$ & $L_{0}$ & $L_{0}$ & $L_{\infty}$ & $L_{\infty}$ & $L_{0}$ & $L_{\infty}$ & $L_{\infty}$ & $L_{\infty}$ & $L_{0}$ & $L_{0}$ \\
\hline \multirow{3}{*}{ Session 2} & MS & $L_{\infty}$ & $L_{0}$ & $L_{0}$ & $L_{0}$ & $L_{0}$ & $L_{0}$ & $L_{0}$ & $L_{2}$ & $L_{0}$ & $L_{0}$ & $L_{0}$ & $L_{2}$ & $L_{0}$ & $L_{0}$ & $L_{1}$ & $L_{1}$ \\
\hline & $\mathrm{T} 1$ & $L_{0}$ & $L_{0}$ & $L_{\infty}$ & $L_{\infty}$ & $L_{\infty}$ & $L_{\infty}$ & $L_{0}$ & $L_{0}$ & $L_{\infty}$ & $L_{\infty}$ & $L_{\infty}$ & $L_{\infty}$ & $L_{0}$ & $L_{\infty}$ & $L_{\infty}$ & $L_{\infty}$ \\
\hline & $\mathrm{T} 2$ & $L_{0}$ & $L_{0}$ & $L_{0}$ & $L_{0}$ & $L_{\infty}$ & $L_{\infty}$ & $L_{0}$ & $L_{\infty}$ & $L_{\infty}$ & $L_{0}$ & $L_{\infty}$ & $L_{0}$ & $L_{\infty}$ & $L_{0}$ & $L_{1}$ & $L_{\infty}$ \\
\hline \multirow{3}{*}{ Session 3} & MS & $L_{0}$ & $L_{0}$ & $L_{0}$ & $L_{0}$ & $L_{0}$ & $L_{1}$ & $L_{0}$ & $L_{0}$ & $L_{1}$ & $L_{0}$ & $L_{0}$ & $L_{1}$ & $L_{\infty}$ & $L_{0}$ & $L_{1}$ & $L_{1}$ \\
\hline & $\mathrm{T} 1$ & $L_{\infty}$ & $L_{0}$ & $L_{0}$ & $L_{0}$ & $L_{\infty}$ & $L_{\infty}$ & $L_{0}$ & $L_{0}$ & $L_{\infty}$ & $L_{\infty}$ & $L_{\infty}$ & $L_{0}$ & $L_{\infty}$ & $L_{0}$ & $L_{0}$ & $L_{0}$ \\
\hline & $\mathrm{T} 2$ & $L_{0}$ & $L_{\infty}$ & $L_{\infty}$ & $L_{0}$ & $L_{\infty}$ & $L_{1}$ & $L_{\infty}$ & $L_{0}$ & $L_{1}$ & $L_{\infty}$ & $L_{0}$ & $L_{0}$ & $L_{0}$ & $L_{0}$ & $L_{\infty}$ & $L_{0}$ \\
\hline
\end{tabular}

Compared to the case of the first experiment (Where we established a fragmented information), in the second experiment, most of the subjects don't seem to follow a level of thinking (cf. Table 12). Generally, subjects' weights are located between $L_{0}$ and $L_{1}$. Their actions, however, approach equilibrium in the last phase of the game. The number of cases in which players opperate the same level of reasoning as in MS-treatment is higher in CH1-treatment than in CH2-treatment (26 versus 20 cases). 42 subjects out of 48 operate the same level of reasoning in two or more treatments. As the game is complicated from structural point of view, $L_{1}$ are not optimally responding to $L_{0}$, whose behaviors are ambiguous. Hence, it is not possible for $L_{1}$ to develop optimal strategies.

Overall, in both games, this result is in accordance with that of Nagel (1995) who finds that subjects tend to adhere to the same level of thinking throughout the study in a pure beauty contest game ${ }^{11}$. The theory of K-level show that limited levels of thinking necessarily lead subjects to underweight the public signal compared to equilibrium predictions where players suppose to place much weight on the public signal (cf. Kübler and Weizsäcker, 2004).

Table 12: Individual behavior of subjects: Groups 7-12

\begin{tabular}{|c|c|c|c|c|c|c|c|c|c|c|c|c|c|c|c|c|c|}
\hline \multicolumn{2}{|c|}{ Subjects } & 1 & 2 & 3 & 4 & 5 & 6 & 7 & 8 & 9 & 10 & 11 & 12 & 13 & 14 & 15 & 16 \\
\hline \multirow{3}{*}{ Session 4} & MS & $L_{1}$ & $L_{0}$ & $L_{1}$ & $L_{1}$ & $L_{0}$ & $L_{0}$ & $L_{0}$ & $L_{1}$ & $L_{0}$ & $L_{0}$ & $L_{0}$ & $L_{0}$ & $L_{0}$ & $L_{0}$ & $L_{1}$ & $L_{0}$ \\
\hline & $\mathrm{CH} 1$ & $L_{0}$ & $L_{0}$ & $L_{0}$ & $L_{1}$ & $L_{0}$ & $L_{0}$ & $L_{1}$ & $L_{\infty}$ & $L_{0}$ & $L_{0}$ & $L_{0}$ & $L_{0}$ & $L_{0}$ & $L_{0}$ & $L_{0}$ & $L_{0}$ \\
\hline & $\mathrm{CH} 2$ & $L_{0}$ & $L_{0}$ & $L_{\infty}$ & $L_{\infty}$ & $L_{\infty}$ & $L_{0}$ & $L_{0}$ & $L_{\infty}$ & $L_{0}$ & $L_{\infty}$ & $L_{0}$ & $L_{\infty}$ & $L_{\infty}$ & $L_{\infty}$ & $L_{\infty}$ & $L_{\infty}$ \\
\hline \multirow{3}{*}{ Session 5} & MS & $L_{0}$ & $L_{1}$ & $L_{1}$ & $L_{0}$ & $L_{1}$ & $L_{1}$ & $L_{1}$ & $L_{1}$ & $L_{1}$ & $L_{1}$ & $L_{0}$ & $L_{0}$ & $L_{0}$ & $L_{0}$ & $L_{0}$ & $L_{1}$ \\
\hline & $\mathrm{CH} 1$ & $L_{1}$ & $L_{\infty}$ & $L_{0}$ & $L_{0}$ & $L_{0}$ & $L_{0}$ & $L_{1}$ & $L_{0}$ & $L_{0}$ & $L_{1}$ & $L_{0}$ & $L_{\infty}$ & $L_{0}$ & $L_{0}$ & $L_{0}$ & $L_{0}$ \\
\hline & $\mathrm{CH} 2$ & $L_{\infty}$ & $L_{1}$ & $L_{0}$ & $L_{0}$ & $L_{\infty}$ & $L_{0}$ & $L_{0}$ & $L_{0}$ & $L_{0}$ & $L_{0}$ & $L_{0}$ & $L_{0}$ & $L_{0}$ & $L_{1}$ & $L_{\infty}$ & $L_{0}$ \\
\hline \multirow{3}{*}{ Session 6} & MS & $L_{0}$ & $L_{0}$ & $L_{0}$ & $L_{0}$ & $L_{0}$ & $L_{0}$ & $L_{0}$ & $L_{0}$ & $L_{0}$ & $L_{0}$ & $L_{0}$ & $L_{0}$ & $L_{0}$ & $L_{0}$ & $L_{0}$ & $L_{0}$ \\
\hline & $\mathrm{CH} 1$ & $L_{0}$ & $L_{0}$ & $L_{1}$ & $L_{1}$ & $L_{\infty}$ & $L_{1}$ & $L_{1}$ & $L_{1}$ & $L_{0}$ & $L_{0}$ & $L_{0}$ & $L_{0}$ & $L_{0}$ & $L_{0}$ & $L_{0}$ & $L_{1}$ \\
\hline & $\mathrm{CH} 2$ & $L_{0}$ & $L_{\infty}$ & $L_{\infty}$ & $L_{0}$ & $L_{0}$ & $L_{0}$ & $L_{\infty}$ & $L_{0}$ & $L_{0}$ & $L_{1}$ & $L_{0}$ & $L_{1}$ & $L_{0}$ & $L_{0}$ & $L_{0}$ & $L_{0}$ \\
\hline
\end{tabular}

Finally, we sum up the main results of this paper in comparing experimental evidence to theoretical predictions in terms of informational disclosure policy (see Table 13).

The study of Cornand and Baeriswyl (2013) didn't permit to choose whether the central bank shall decrease the precision of the information (partial publicity) or disclose the information to only a fraction of the economic agents. Neverthless, while the precision of public information doesn't seem to have an impact on subjects' behavior, the above authors recommend a communication strategy that is based on varying the precision of the central bank's information rather than disclosing the same information to a limited audience.

\footnotetext{
${ }^{11}$ Cornand and Baeriswyl (2013) found a similar observation. Note that those authors use the notation $L_{1}$ and $L_{2}$ which correspond to $L_{0}$ and $L_{1}$ in our case.
} 
Table 13: Theoretical versus experimental observations

\begin{tabular}{|c|c|c|c|}
\hline Basic framework & Theoretical predictions & $\begin{array}{l}\text { Experimental re- } \\
\text { sults (Cornand and } \\
\text { Baeriswyl, 2013) }\end{array}$ & Experimental results (Ours) \\
\hline $\begin{array}{l}\text { one public signal }+ \text { one } \\
\text { private signal (Morris } \\
\text { and Shin) }\end{array}$ & $\begin{array}{l}\text { The public signal serves } \\
\text { as a focal point. It leads } \\
\text { to an overreaction prob- } \\
\text { lem by the agents. }\end{array}$ & $\begin{array}{l}\text { Overreaction is de- } \\
\text { tected but not as } \\
\text { strong as the theory } \\
\text { predicts. }\end{array}$ & $\begin{array}{l}\text { Overreaction is ob- } \\
\text { served and detected but } \\
\text { not as strong as the } \\
\text { theory predicts. }\end{array}$ \\
\hline $\begin{array}{l}\text { one public signal to } \\
\text { a proprtion } \mathrm{P} \text { of the } \\
\text { agents }+ \text { one private } \\
\text { signal (Cornand and } \\
\text { Heinemann }(2008)\end{array}$ & $\begin{array}{l}\text { A more precise public } \\
\text { information disclosed to } \\
\text { a proportion } P \text { of the } \\
\text { agents. } \\
\rightarrow \text { overreaction is re- } \\
\text { duced and welfare is en- } \\
\text { hanced. }\end{array}$ & $\begin{array}{l}\text { Overreaction is persis- } \\
\text { tent even in the case } \\
\text { of establishing partial } \\
\text { communication strate- } \\
\text { gies. } \\
\text { There are differences } \\
\text { between weights in } \\
\text { partial publicity and } \\
\text { partial transparency } \\
\text { treatments, resp. } \\
\text { Agents' behavior is } \\
\text { not sensitive to vary- } \\
\text { ing the precision of } \\
\text { public information. }\end{array}$ & $\begin{array}{l}\text { Overreaction is eff- } \\
\text { ciently reduced. }\end{array}$ \\
\hline $\begin{array}{l}n \text { semi-public signal }+ \\
\text { one private signal (Tra- } \\
\text { belsi, 2012) }\end{array}$ & $\begin{array}{l}\text { The semi-public signal } \\
\text { serves as a focal point to } \\
\text { agents belonging to the } \\
\text { same group. As it differ } \\
\text { from a group to another, } \\
\text { agents will no more ig- } \\
\text { nore their proper signal. }\end{array}$ & None & $\begin{array}{l}\text { Overreaction is reduced } \\
\text { more efficiently when } \\
\text { the fragmentation mea- } \\
\text { sure is high. }\end{array}$ \\
\hline
\end{tabular}

Our main economic conclusion of our exprimental study is that by either establishing a partial publicity or a fragmented information, the central bank could alleviate overreaction that was meant to lead to a harmful effect to social welfare. From a practical point of view and given the previous results of the study of Cornand and Baeriswyl (2013), fragmentation would be more feasible to be implemented than a partial publicity given the widespread of the media.

Both experimental studies offer ways for central bankers to think strategically about solutions that focus on the best practices and adding values. A recent incident of the Swiss National Bank (SNB) can illustrate markets' overreaction (published in LeTemps.ch). In fact, statements of SNB concerning equities have generated a loss of more than two billion swiss franc of market capitalization, giving suspicion of insider trading. This fact incited SNB to review its communication policy .

\section{Concluding remarks}

The goal of this paper is to discuss the efficiency of two different partial transparency strategies, by making them comparable to a policy where the central bank's private information is fully available to all agents (subjects). To do that, we generalize the classical beauty contest setting by using the models of Cornand and Heinemann (2008) and Trabelsi (2012), respectively, that are initially derived from the canonical framework of Morris and Shin (2002). Having the experimental design based on Morris and Shin model generates an environment that is more complex than the one used in theory. All payoff function and optimal decision action were re-designed in order to fit the reality, where the number of subjects is finite. The paper provides support both for and against global game's theoretical approach as well as the models of K-level thinking. We conjecture that the reason of these results is that our informational structure involves a private information and that the coordination motive is not sufficiently high. Moreover, as observed behavior is not sensitive to the details of information structure, 
the precision of information should not be taken into account in future research (Through comparative statistics, Cornand and Baeriswyl (2013) didn't find any significance of the effect of the relative precision of public and private signals on subjects' behavior. This is a supplementary justification that we didn't vary the precision of information in our experiment.), but rather we should study the effect of information and other payoff relevant parameters on strategic uncertainty.

\section{References}

[1] Amador, M., and P. O. Weil (2006), "Learning from Private and Public Observations of others actions," Working paper, Stanford/NYU Stern.

[2] Amato, J., S. Morris, and H. S. Shin (2002), "Communication and Monetary Policy", Oxford Review of Economic Policy, 18(4), 495-503.

[3] Angeletos, G. M., and A. Pavan (2004), "Transparency of Information and Coordination in Economies with Investment Complementarities," American Economic Review (Papers and Proceedings), 94, 91-98.

[4] Angeletos, G. M., and A. Pavan (2007), "Efficient Use of Information and Social Value of Information," Econometrica, 75(4), 1103-1142.

[5] Blinder, A., Ehrmann, M., Fratzscher, M., de Haan, J. and Jansen, D.-J. (2008), "Central bank communication and monetary policy: A survey of theory and evidence." Journal of Economic Literature 46(4), 910-45, December.

[6] Cornand, C., and F. Heinemann (2008), "Optimal Degree of Public Information Dissemination," Economic Journal 118(518), 718-734.

[7] Cornand, C., and R. Baeriswyl (2013), "Reducing overreaction to central bank's disclosure: theory and experiment", forthcoming in Journal of European Economic Association.

[8] Cornand, C., and F. Heinemann (2013), "Measuring agents' reaction to private and pblic information in games with strategic complementaritites", forthcoming in Experimental Economics.

[9] Fishbacher, U. (2007), "z-Tree: Zurich toolbox for ready-made economic experiments," Experimental Economics 10(2), 171-178, June.

[10] Gai, P., and H. S. Shin (2003), "Transparency and financial stability", Financial Stability Review, December.

[11] Morris, S., and H. S. Shin (2002), "The Social Value of Public Information," American Economic Review $92,1521-1534$.

[12] Morris, S., and H. S. Shin (2007), "Optimal Communication," Journal of the European Economic Association $5(2-3), 594-602$.

[13] Nagel, R. (1995), "Uneravaling in guessing games: An exprimental study", American Economic Review 49, 1313-1326.

[14] Kübler D., G. Weizsäcker (2004), "Limited Depth of Reasoning and Failure of Cascade Formation in the Laboratory," Review of Economic Studies 71, 425-442.

[15] Padoa-Schioppa, T. (2004), Interview in Wall Street Journal, 15 July 2004.

[16] Shapiro, D., X. Shi, and A. Zillante (2010), "Robustness of K-level reasoning in generalized beauty contest games," Mimeo. http://homes.chass.utoronto.ca/ xshi/levelk.pdf

[17] Stahl, D.O., and P.W. Wilson (1994), "Experimental evidence on players' models of other players", Journal of Econmic Behaviour and Organization 25, 309-327.

[18] Svensson, L.E (2006), "Social Value of public Information: Morris and Shin (2002) is actually protransparency, not cons", American Economic Review, 96(1), 448-451. 
[19] Trabelsi, E. and M. Ayadi (2011), "The role of central bank transparency in a macroeconomic perspective: Evidence from a pooled Cross-country setting", The Empirical economics Letters 10(9), 927-934.

[20] Trabelsi, E. (2012), "How avoiding overreaction to public information? Some insights on central bank communication practices," EERI Research Paper Series EERI_RP_2012_14, Economics and Econometrics Research Institute (EERI), Brussels. http://www.eeri.eu/documents/wp/EERI_RP_2012_14.pdf

[21] Woodford, M. (2003), "Interest and Prices: Foundations of a Theory of Monetary Policy", Princeton: Princeton University Press.

[22] Woodford, M. (2005), "Central-Bank Communication and Policy Effectiveness." In The Greenspan Era: Lessons for the Future. Kansas City: Federal Reserve Bank of Kansas City, 399-474.

\section{Aknowledgment}

The authors are grateful to precious comments from participants to the 4th ASFEE (French Experimental Economics Association Meeting) in Lyon and to the participants of EFC2013 (Experimental Finance Conference) at Tilburg. This work is realized as a part of a cooperation project CNRS-DGRST (ISG Tunis \& GATE-LSE Laboratory of Lyon) and was performed within the framework of the LABEX CORTEX (ANR-11- LABX-0042) of University of Lyon, within the program "Investissements d'Avenir" (ANR-11-ID EX-007) operated by the French National Research Agency (ANR).

\section{A General instructions (Translated from French to English)}

Thanks for participating to an economic experiment. You cannot communicate with other participants. You belong to a group of 8 players. This session consists of 3 stages, each one lasts for 15 periods. Your main task is to try to guess the value of the true state V. All what you have to do is to submit a number. Returns will be determined by the following two factors:

- The true state V (unknown)

- The average decision made by the other players of your group

At the time when you make your decisions, you will not know either of these two factors. You will need to decide based on the information that will be made available to you.

\section{Your profit and cash payments}

Your profit will be calculated as follows. In the beginning of each round you will be given 400 ECU. From this amount, we will deduct points when your action does not match the true state. We will also deduct points when your action does not match the average decisions made by others. Your final profit will be calculated according to the following formula:

$$
\text { Payoff }=400-2.5 \times(\text { your decision }-V)^{2}-7.5 \times(\text { your decision }- \text { average decision of others })^{2}
$$

The first term says that your action will bring you at most 400 ECU. The second term determines your loss from mismatching the true state. The third term determines your loss from mismatching the average decisions made by others. In the case of negative payoff, the computer screen will report a zero gain. You find below some examples:

\begin{tabular}{|l|c|c|c|c|}
\hline \multicolumn{1}{|c|}{$\mathrm{V}$} & 50 & 409 & 100 & 256 \\
\hline \hline $\begin{array}{l}\text { Private } \\
\text { signal }\end{array}$ & 41 & 408 & 101 & 249 \\
\hline Public signal & 46 & 415 & 108 & 257 \\
\hline $\begin{array}{l}\text { Your deci- } \\
\text { sion }\end{array}$ & 44.2 & 410.5 & 107.5 & 250 \\
\hline $\begin{array}{l}\text { Average deci- } \\
\text { sion of others }\end{array}$ & 45 & 413.2 & 104.5 & 263 \\
\hline $\begin{array}{l}\text { profit/gain } \\
\text { in Units }\end{array}$ & 365.72 & 390.46 & 334.75 & 195 \\
\hline
\end{tabular}


The profit that you made in each period will be converted into cash by the following procedure: The session lasts for 45 periods. Your cash earnings will be equal to the total profit that you earned during these 45 periods: 1000 units are converted into 1 Euro.

\section{A.1 Instructions relative to stage 1 of sessions $1,2,3,4,5$ and 6 (MS)}

For each of the 15 periods, a value of the true state $\mathrm{V}$ is randomly drawn from a certain interval. You will not know the value of $\mathrm{V}$.

\section{Guessing the true state}

In the beginning of each period, you and all other participants in your session will receive two signals that will provide you with information about the true state:

- A common signal (public information) randomly drawn from the interval [V-10, V+10]

- A private signal drawn from the interval $[\mathrm{V}-10, \mathrm{~V}+10]$, independently from the common signal. Here is what you know and what you don't know about the information available to other players in your group:

- They receive two signals, just like you do;

- You know the first signal that everyone receives. It is common. All players in your session will have the same signal.

- You do not know the second signal that they receive. The second signal is a private signal. It means that you cannot see private signals received by other players. It also means that they cannot see the private signal that you receive.

\section{A.2 Instructions relative to stage 2 of sessions 1,2 , and 3 (T1)}

For each of the 15 periods, a value of the true state $\mathrm{V}$ is randomly drawn from a certain interval. You will not know the value of $\mathrm{V}$. The rules are similar to the stage 1, except the subjects will be divided into 2 sub-groups:

- Sub-group 1 contains 4 participants

- Sub-group 2 contains 4 participants

\section{Guessing the true state}

- If you belong to the sub-group 1, you and 3 other participants will receive 2 signals;

1. a common signal to 4 participants randomly drawn from $[\mathrm{V}-10, \mathrm{~V}+10]$

2. a private signal randomly drawn from $[\mathrm{V}-10, \mathrm{~V}+10]$, independently from the first signal

- If you belong to the sub-group 1, you and 3 other participants will receive 2 signals;

1. a common signal to 4 participants randomly drawn from $[\mathrm{V}-10, \mathrm{~V}+10]$

2. a private signal randomly drawn from $[\mathrm{V}-10, \mathrm{~V}+10]$, independently from the first signal

You choose then a value of $\mathrm{V}$ between both signals you receive.

Your profit depends on the deviation from the true state as well as the deviation from the average decision of your 7 opponents.

The number of players in each sub-group is the same during all periods. The players are randomly matched during the first period, then the matching remains stable during the rest of the 14 periods. 


\section{A.3 Instructions relative to stage 3 of sessions 1,2, and 3 (T2)}

For each of the 15 periods, a value of the true state $\mathrm{V}$ is randomly drawn from a certain interval. You will not know the value of $\mathrm{V}$. The rules are similar to the stage 1, except the subjects will be divided into 4 sub-groups:

- Sub-group 1 contains 2 participants

- Sub-group 2 contains 2 participants

- Sub-group 3 contains 2 participants

- Sub-group 4 contains 2 participants

\section{Guessing the true state}

Whatever the sub-group to which you belong, you and 1 other participant will receive 2 signals;

1. a common signal to 2 participants randomly drawn from $[\mathrm{V}-10, \mathrm{~V}+10]$

2. a private signal randomly drawn from $[\mathrm{V}-10, \mathrm{~V}+10]$, independently from the first signal

You choose then a value of $\mathrm{V}$ between both signals you receive.

Your profit depends on the deviation from the true state as well as the deviation from the average decision of your 7 opponents.

The number of players in each sub-group is the same during all periods. The players are randomly matched during the first period, then the matching remains stable during the rest of the 14 periods.

\section{A.4 Instructions relative to stage 2 of sessions 4,5 , and 6 (CH1)}

For each of the 15 periods, a value of the true state $\mathrm{V}$ is randomly drawn from a certain interval. You will not know the value of $\mathrm{V}$. The rules are similar to the stage 1, except the subjects will be divided into 2 sub-groups:

- Sub-group 1 contains 4 participants

- Sub-group 2 contains 4 participants

\section{Guessing the true state}

- If you belong to the sub-group 1, you will receive 2 signals; a common signal and a private signal. You decide then on the basis of these 2 signals.

You choose then a value of $\mathrm{V}$ between both signals you receive.

- If you belong to sub-group 2, you will only receive a private signal and then you have to decide according to that specific signal.

Your profit depends on the deviation from the true state as well as the deviation from the average decision of your 7 opponents.

The number of players in each sub-group is the same during all periods. The players are randomly matched during the first period, then the matching remains stable during the rest of the 14 periods.

\section{A.5 Instructions relative to stage 3 of sessions 4,5, and 6 (CH2)}

For each of the 15 periods, a value of the true state $\mathrm{V}$ is randomly drawn from a certain interval. You will not know the value of $\mathrm{V}$. The rules are similar to the stage 1, except the subjects will be divided into 2 sub-groups:

- Sub-group 1 contains 2 participants

- Sub-group 2 contains 6 participants

\section{Guessing the true state}

You receive two signals: 
- If you belong to the sub-group 1, you will receive 2 signals; a common signal and a private signal. You decide then on the basis of these 2 signals.

You choose then a value of $\mathrm{V}$ between both signals you receive.

- If you belong to sub-group 2, you will only receive a private signal and then you have to decide according to that specific signal.

Your profit depends on the deviation from the true state as well as the deviation from the average decision of your 7 opponents.

The number of players in each sub-group is the same during all periods. The players are randomly matched during the first period, then the matching remains stable during the rest of the 14 periods.

\section{B Questionnaire}

\section{B.1 Training questions (starting sessions 1 to 3 ) T1 \& T2}

Q1 In stage 1, you receive 2 signals: Common signal $=145.7$, private signal $=138$, then the true state is :

- between 135.7 and 148

- between 138 and 145.7

- between 148 and 155.7

Q2 In stage 2, you receive 2 signals: Common signal $=352.4$, private signal $=344.2$, then the true state is:

- between 344.2 and 352.4

- between 342.4 and 354.2

- between 350.4 and 354.2

Q3 Fill in the blanks: At stage 2, the 8 players will be divided into ... sub-groups, the sub-group 1 contains... players. In each period, the players who belong to the sub-group1 receive ... common signal and ....private signal. The players who belong to the sub-group1 receive ... common signal and ....private signal.

\section{Q4 Profit formula}

1. The true state equals to 256 , your decision $=249$, and the average decision of your opponents is 240 , write the formulae of your gain:

2. To maximize your profit, it is more important your decision be close to the unknown true state than to the decision of the other players? Yes No

\section{B.2 Training questions (starting sessions 4 to 6) $\mathrm{CH} 1$ \& $\mathrm{CH} 2$}

Q1 In stage 1 , you receive 2 signals: Common signal $=145.7$, private signal $=138$, then the true state is :

- between 135.7 and 148

- between 138 and 145.7

- between 148 and 155.7

Q2 In stage 2, you only receive a private signal $=127$, then your decision will be: ..... 


\section{Q3 Profit formula}

1. The true state equals to 256 , your decision $=249$, and the average decision of your opponents is 240 , write the formula of your gain:

2. To maximize your profit, it is more important your decision be close to the unknown true state than to the decision of the other players? Yes No

\section{Examples of screen layout}

Screen $n^{\circ} 1$ : Decision phase

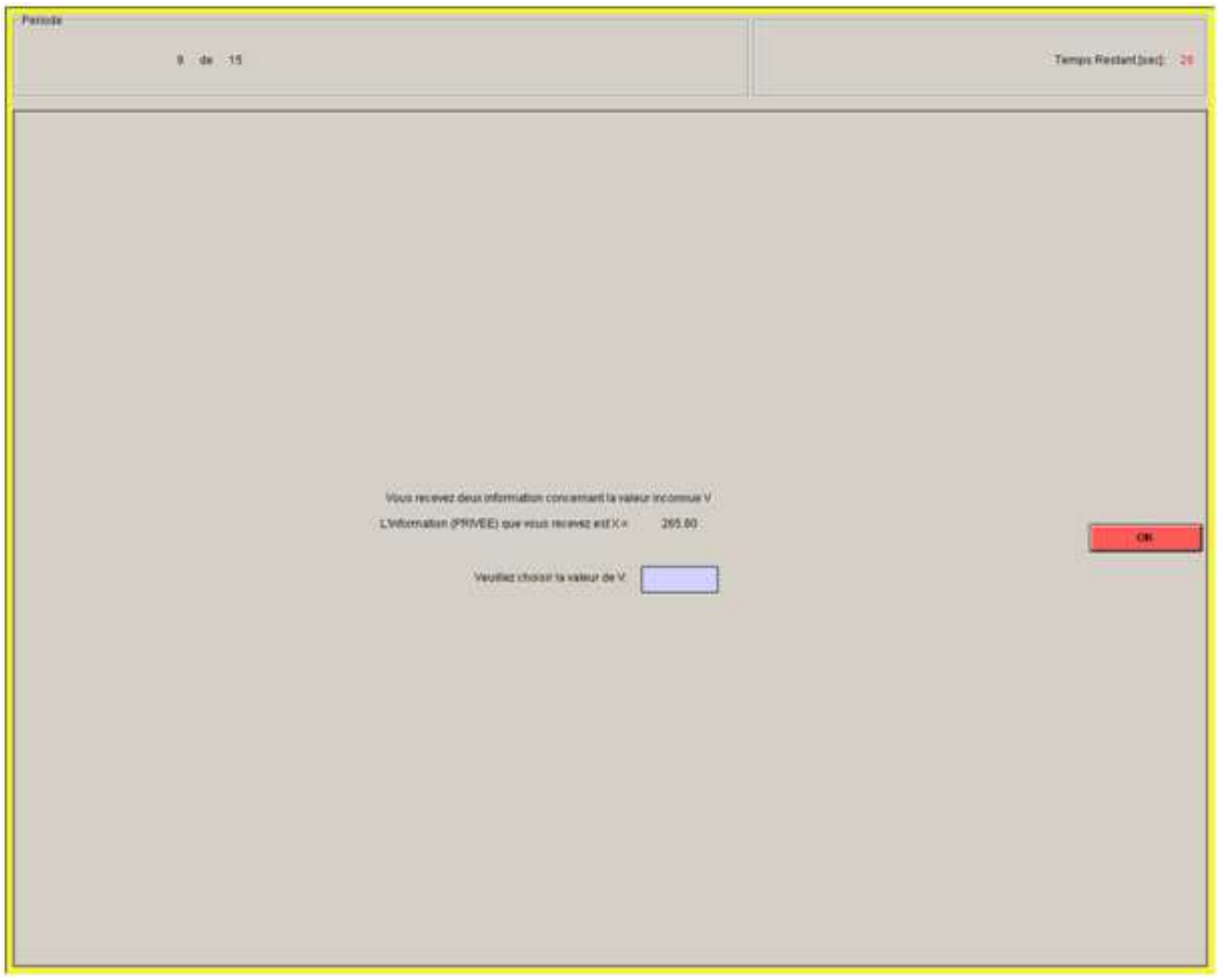

Screen $n^{\circ} 2$ : Information phase 


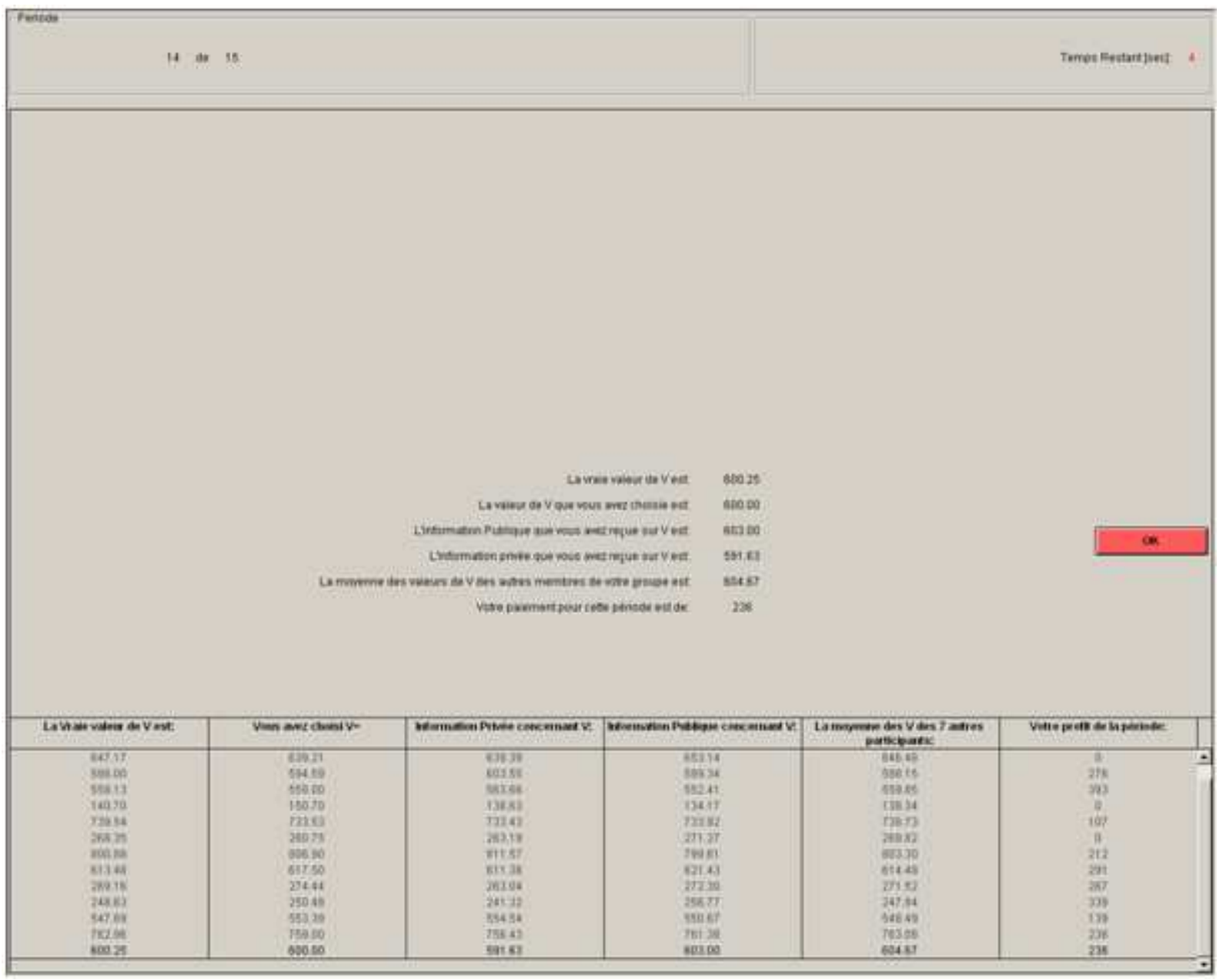

\section{Parameters values in the expected utility function}

TABLE 14: Parameters values in the expected utility function

\begin{tabular}{|c|c|c|c|c|c|c|c|}
\hline & MS & T1 & T2 & & MS & CH1 & CH2 \\
\hline \hline$\lambda$ & 0.8 & 0.5957 & 0.5283 & $\lambda$ & 0.8 & 0.5957 & 0.5283 \\
\hline$\lambda^{\prime}$ & & 0.3404 & 0.4528 & $\hat{\lambda}$ & & 0.2553 & 0.088 \\
\hline$\lambda^{*}$ & & 0.3404 & 0.1509 & $\hat{\lambda}$ & & 0.3404 & 0.1509 \\
\hline
\end{tabular}

